\title{
Attenuated DNA damage repair delays therapy-related myeloid neoplasms in a mouse model
}

\author{
Kit I Tong*,1, Kazushige Ota ${ }^{2}$, Akiyoshi Komuro ${ }^{2}$, Takeshi Ueda ${ }^{2}$, Akihiko Ito ${ }^{3}$, C Anne Koch ${ }^{4,5}$ and Hitoshi Okada*,1,2,56
}

Therapy-related cancers are potentially fatal late life complications for patients who received radio- or chemotherapy. So far, the mouse model showing reduction or delay of these diseases has not been described. We found that the disruption of Aplf in mice moderately attenuated DNA damage repair and, unexpectedly, impeded myeloid neoplasms after exposure to ionizing radiation (IR). Irradiated mutant mice showed higher rates of p53-dependent cell death, fewer chromosomal translocations, and a delay in malignancy-induced mortality. Simultaneous deficiency of p53 abrogated IR-induced apoptosis and the benefit of impaired DNA repair on mortality in irradiated $\mathrm{Aplf}^{-1}$ mice. Depletion of APLF in non-tumorigenic human cells also markedly reduced the risk of radiation-induced chromosomal aberrations. We therefore conclude that proficient DNA damage repair may promote chromosomal aberrations in normal tissues after irradiation and induce malignant evolution, thus illustrating the potential benefit in sensitizing p53 function by manipulating DNA repair efficiency in cancer patients undergoing genotoxic therapies.

Cell Death and Disease (2016) 7, e2401; doi:10.1038/cddis.2016.298; published online 6 October 2016

In USA alone therapy-related cancers, either hematological or solid, among cancer survivors account about $18 \%$ of all incident cancers, surpassing primary cancers of the breast, lung, and prostate. ${ }^{1}$ Therapy-related myeloid neoplasms (t-MNs) include therapy-related myelodysplastic syndrome (t-MDS) and acute myeloid leukemia (t-AML). Patients with $\mathrm{t}-\mathrm{MDS}$ or $\mathrm{t}-\mathrm{AML}$ have similar survival rates while patients with complex and unfavorable karyotypes tend to have poorer prognosis regardless of morphologic presentation and myeloblast percentage. ${ }^{2}$ Mutations in TP53 and ATM (ataxia telangiectasia mutated) are considered risk factors due to their important roles in the DNA damage response (DDR) pathways. ${ }^{3,4}$ At present there is no active medical intervention to prevent the risk of these therapyinduced cancers. In addition, mouse models that demonstrate a delay of therapy-related malignancies have not yet been described.

Genotoxic therapies generate DNA damage, including potentially deleterious DNA double-strand breaks (DSBs) that may be repaired by non-homologous end joining (NHEJ). ${ }^{5,6}$ NHEJ does not utilize extensive homology for DSB end joining and is active throughout the entire cell cycle. NHEJ consists of the classical (C-NHEJ) and alternative (A-EJ) NHEJ pathways. $^{6,7}$ The C-NHEJ pathway enables direct joins and low microhomology usage (1-3 nucleotides (nt)) at DSB repaired junctions, and A-EJ prefers longer microhomologymediated end joining ( $\geq 4 \mathrm{nt})$ at ligation sites.

Aprataxin and PNKP-like factor (APLF, also referred to as Xip1, C2orf13, and PALF) is a poly(ADP-ribose) or PARbinding protein that interacts with $\mathrm{C}$-NHEJ repair factors, XRCC4-DNA ligase 4 and $\mathrm{Ku}$, to facilitate C-NHEJ in a PAR polymerase 3 (PARP3)-dependent manner. ${ }^{8-10}$ APLF can undergo ATM- and PARP3-dependent phosphorylation at serine-116 following ionizing radiation (IR), which is critical for the recruitment of APLF to the sites of DNA lesion to resolve $\gamma \mathrm{H} 2 \mathrm{AX}$ DNA damage signals. ${ }^{11}$ Accumulation of APLF to DSBs has been demonstrated to promote the retention of XRCC4/DNA ligase 4 complex in chromatin to facilitate DNA ligation during C-NHEJ. ${ }^{10}$ Furthermore, a phospho-ablative mutant of APLF (APLF $\left.{ }^{\mathrm{S} 116 \mathrm{~A}}\right)$, which disabled IR-induced phosphoryation at serine-116 of APLF, exhibited higher persistent $\gamma \mathrm{H} 2 \mathrm{AX}$ DNA damage signal and lower cellular survival in colony formation assays after IR exposure reminiscent of cells with APLF depletion. ${ }^{11}$ These data suggest that APLF works downstream of ATM and PARP3 to modulate C-NHEJ after IR treatment.

\footnotetext{
${ }^{1}$ The Campbell Family Institute for Breast Cancer Research, Ontario Cancer Institute, University Health Network, Toronto, ON, Canada M5G 2M9; ${ }^{2}$ Department of Biochemistry, Kindai University Faculty of Medicine, 377-2 Ohno-Higashi, Osaka-Sayama 589-8511, Osaka, Japan; ${ }^{3}$ Department of Pathology, Kindai University Faculty of Medicine, 377-2 Ohno-Higashi, Osaka-Sayama, Osaka 589-8511, Japan; ${ }^{4}$ Radiation Medicine Program, Princess Margaret Cancer Center, University Health Network, Toronto, ON, Canada M5G 2M9; ${ }^{5}$ Department of Medical Biophysics, University of Toronto, Toronto, ON, Canada M5G 2M9 and ${ }^{6}$ Anti-Aging Center, Kindai University, Higashi-Osaka, Osaka 577-8502, Japan

*Corresponding author: KI Tong or H Okada, Department of Biochemistry, Kindai University Faculty of Medicine, 377-2 Ohno-Higashi, Osaka-Sayama 589-8511, Osaka, Japan. Tel: +81723660221 Ext 3153; Fax: +81723660245; E-mail: kittong@uhnres.utoronto.ca or hokada@med.kindai.ac.jp

Abbreviations: APLF, aprataxin and polynucleotide kinase/phosphatase (PNKP)-like factor; Xip1, XRCC1-interacting protein 1; C2orf13, chromosome 2 open reading frame 13; PALF, PNK and APTX-like FHA protein; IR, ionizing radiation; t-MNs, therapy-related myeloid neoplasms; t-MDS, therapy-related myelodysplastic syndrome; tAML, therapy-related acute myeloid leukemia; ATM, ataxia telangiectasia mutated; ATR, ATM and RAD3-related; DSB, DNA double-strand break; DDR, DNA damage response; NHEJ, non-homologous end joining; C-NHEJ, classical NHEJ; A-EJ, alternative NHEJ; nt, nucleotides; PAR, poly(ADP-ribose); PARP3, PAR polymerase 3; ROS, reactive oxygen species; XRCC4, X-ray repair cross-complementary protein 4; PNKP, polynuceotide kinase/phosphatase; CSR, class switch recombination; IgH, immunoglobulin heavy chain; MEFs, mouse embryonic fibroblasts; DNA-PKcs, DNA-dependent protein kinase catalytic subunit; Gy, Gray; mGy, milliGray; KD, knock down; WT, wild type; RARA, retinoic acid receptor alpha; FLT3, Fms-like tyrosine kinase 3; PTPN11, tyrosine-protein phosphatase non-receptor type 11; NRAS, neuroblastoma RAS viral oncogene homolog; LPS, lipopolysaccharides; PI, propidium iodide; ES, embryonic stem; CEBPA, CCAAT/enhancer-binding protein alpha Received 21.12.15; revised 31.7.16; accepted 22.8.16; Edited by M Agostini
} 
lonizing radiation and reactive oxygen species (ROS) generate DSBs with chemically modified ends, which require DNA end processing before end joining. Nucleases such as Artemis and APLF, and end processing enzymes such as PNKP (polynuceotide kinase/phosphatase), may participate in processing IR- or ROS-damaged DNA ends for DNA damage repair. ${ }^{6}$

Here we report that a moderate reduction of C-NHEJ activity by the depletion of APLF impedes radiation-induced oncogenic translocation in normal tissues and malignancyassociated mortality.

\section{Results}

Aplf $^{-1-}$ mice are moderately impaired in C-NHEJ activity without a switch to A-EJ. To assess the in vivo contribution of the NHEJ pathway in therapy-induced malignancies, we used a mouse model with reduced C-NHEJ activity by creating a frameshift disruption of the entire coding region of APLF (Supplementary Figure S1), in contrast to an earlier published APLF gene-trapped mouse model, ${ }^{10}$ whereby only the C-terminal half of the APLF was deleted leaving the binding sites for XRCC1/4 and Ku80 intact. ${ }^{9,12}$ Although the C-NHEJ pathway functions in $V(D) J$ recombination for $\mathrm{B}-$ and $\mathrm{T}$-cell development ${ }^{13}$ and in class switch recombination $(\mathrm{CSR})^{14}$ of immunoglobulin heavy chain $(\mathrm{lgH}), \mathrm{Aplf}^{-1-}$ mice exhibited normal B- and T-cell development with mild reduction in the total count of splenocytes (Supplementary Figures S2A-C) and efficient CSR (Supplementary Figures S2D and E), suggesting that APLF is either not functional or functionally redundant in the immune system. In contrast, mouse embryonic fibroblasts (MEFs) from Aplf ${ }^{-1}$ mice showed reduced NHEJ activity (Figure 1a) consistent with previous studies in human cell lines with depletion of APLF expression. $^{9}$ On the other hand, Aplf ${ }^{-1-}$ mice displayed a reduction, albeit not elimination, ${ }^{7}$ of direct joins in the CSR switch junctions (Figure $1 \mathrm{~b}$ and Supplementary Figure S3). ${ }^{10}$ Importantly, there was a concurrent increase of very short microhomology of one nucleotide at switch junctions, suggesting a change in the repairing pattern within the C-NHEJ pathway. Nevertheless, there was no significant increased use of longer microhomology ( $\geq 4 \mathrm{nt}$ ) and, therefore, we did not observe a switch from the C-NHEJ to the A-EJ pathway in $A p / f^{-1-}$ mice (Figures $1 \mathrm{~b}$ and $\mathrm{C}$ and Supplementary Figure S3). Additional depletion of APLF in mice with Atm null background $\left(\right.$ Aplf $\left.^{-1} \mathrm{Atm}^{-1}\right)$ further decreased the number of direct joins compared with $\mathrm{Atm}^{-1-}$ mice reinforcing the notion that APLF is one of the factors in the C-NHEJ pathway (Figures $1 \mathrm{~b}$ and $\mathrm{c}$ and Supplementary Figure S3). Together with the normal CSR activity in Aplf ${ }^{-1-}$ mice (Supplementary Figures S2D and E), these data strongly suggest that there is a moderate attenuation of C-NHEJ activity in these $A$ plf ${ }^{-1}$ mice but the C-NHEJ pathway is functional and still predominating without switching to the A-EJ pathway. Loss of APLF may be compensated partially by other C-NHEJ factors to support C-NHEJ activity and to prevent a switch to the A-EJ pathway. As a major loss of C-NHEJ function, such as the deficiency of DNA-PKcs, Ku70, Ku80, XRCC4, DNA ligase 4, or Artemis, can lead to a number

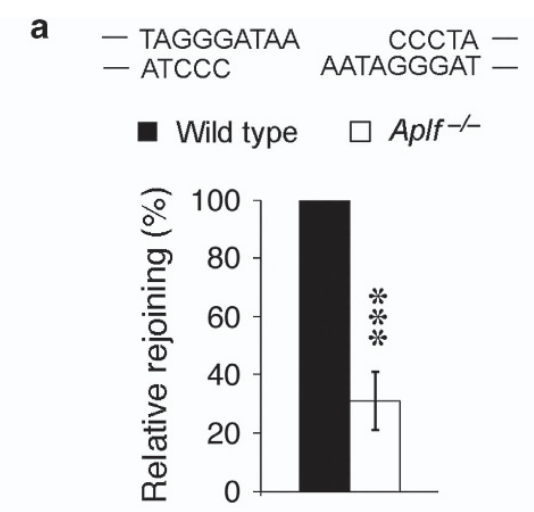

b
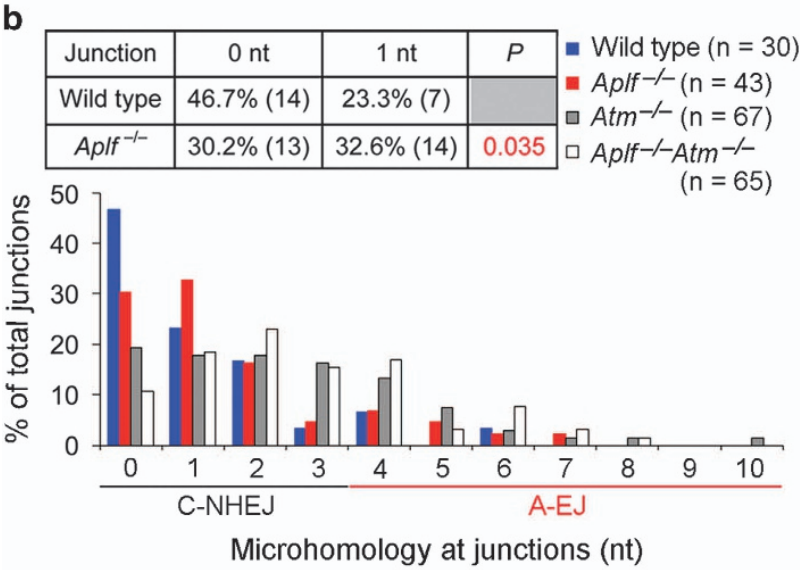

C

\begin{tabular}{|c|c|c|c|}
\hline & C-NHEJ & A-EJ & C-NHEJ $\rightarrow$ A-EJ \\
\hline Junction & $0-3 \mathrm{nt}$ & $\geq 4 \mathrm{nt}$ & $P($ versus WT) \\
\hline Wild type & $90 \%(27)$ & $10 \%(3)$ & \\
\hline Aplf ${ }^{-1-}$ & $83.7 \%(36)$ & $16.3 \%(7)$ & 0.293 (ns) \\
\hline $\mathrm{Atm}^{-1-}$ & $71.6 \%(48)$ & $28.4 \%(19)$ & 0.002 \\
\hline Aplf $^{-1-}$ Atm $^{-1-}$ & $67.7 \%(44)$ & $32.3 \%(21)$ & 0.0002 \\
\hline
\end{tabular}

Figure $1 \mathrm{Aplf}^{-1-}$ mice have lower extrachromosomal NHEJ and less DNA direct end joining at the switch junctions in B cells, but no switch to the alternative NHEJ (AEJ) pathway. (a) Extrachromosomal NHEJ assays of I-Scel digested incompatible DNA ends. Data are means \pm standard deviation (S.D.) $(n=6)$ relative to wild-type controls. ${ }^{* * *} P<0.001$; unpaired two-tailed Student's $t$-test. (b) Microhomology at $\mathrm{S} \mu-\mathrm{S} \gamma 1$ junctions. The number of clones $(n)$ sequenced was compiled from five independent experiments. nt, number of nucleotides at switch junctions. $P<0.05$ is considered statistically significant; two-tailed Fisher's exact test. (c) Frequencies of C-NHEJ ( $0-3 \mathrm{nt})$ and A-EJ ( $\geq 4 \mathrm{nt})$ at the $\mathrm{S}_{\mu}-\mathrm{S} \gamma 1$ switch junctions. The $P$-values were evaluated by two-tailed Fisher's exact test against wild-type controls. NS, not significant

of intrinsic health issues such as growth defects, immunodeficiency, or inherent chromosomal instabilities, ${ }^{13,15}$ the $A$ plf ${ }^{-1}$ mouse, with moderate impairment of the C-NHEJ pathway and specific sensitivities to genotoxic treatments, becomes a good model to address therapy-induced malignant evolution.

Aplf ${ }^{-1-}$ mice have higher p53-mediated cell death upon IR, but less dividing cells with DNA damage and lower frequency of translocation. Following IR, isolated thymocytes from $\mathrm{Aplf}^{-1-}$ mice in culture medium exhibited increased 
cell death after exposure to 2 and 3 Gray (Gy) (Figure 2a). Thymus of $\mathrm{Aplf}^{-1-}$ mice exposed to whole-body irradiation at 6 Gy also showed elevated p53-dependent apoptosis $(4.1 \%$ in WT, $21.2 \%$ in Aplf $^{--}, 0 \%$ in Aplf $^{--} \mathrm{p53}^{--}$) (Figure 2b). Following IR treatment, $\gamma \mathrm{H} 2 \mathrm{AX}$ can be induced by ATMmediated DDR ${ }^{16,17}$ and by DNA-PK during apoptotic DNA fragmentation. ${ }^{18}$ In line with this, isolated bone marrow cells of $\mathrm{Aplf}^{-1}$ mice in culture medium had higher $\gamma \mathrm{H} 2 \mathrm{AX}$-positive cells hours following exposure to 2 Gy IR (Figure $2 \mathrm{c}$ and Supplementary Figures S4), IR induced elevated level of stabilized p53 (Supplementary Figure S11), and IR enhanced p53 downstream target genes (Supplementary Figures S9A and $B$ ), indicating persistent DNA damage and likely higher apoptosis in the mutant mice. Since IR-induced DDR can a

\begin{tabular}{|c|c|c|c|c|c|}
\hline \multicolumn{5}{|c|}{ Mean percentage of Live Cells (\%) } \\
\hline Gy & 1 & 2 & 3 & 4 & 5 \\
\hline Wild type & 69.3 & 66.7 & 46.6 & 35.2 & 24.7 \\
\hline Aplf $^{--}$ & 70.3 & 45.8 & 31.2 & 26.6 & 30.2 \\
\hline
\end{tabular}

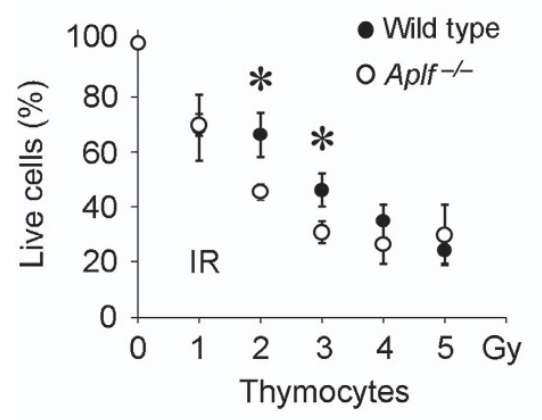

b

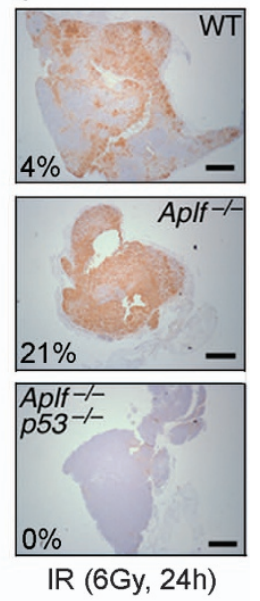

C

\begin{tabular}{|c|c|c|c|c|c|c|c|}
\hline \multicolumn{7}{|c|}{$\gamma$ H2AX positive cells after 2 Gy $(\%)$} \\
\hline Time (h) & $\mathrm{C}$ & 0.5 & 1 & 2 & 4 & 6 & 8 \\
\hline Wild type $^{\prime}$ & 2.6 & 74.7 & 71.4 & 45.9 & 41.8 & 23.5 & 15.1 \\
\hline Aplf $^{--}$ & 2.2 & 77.1 & 77.5 & 55.1 & 45.7 & 27.9 & 20.4 \\
\hline
\end{tabular}

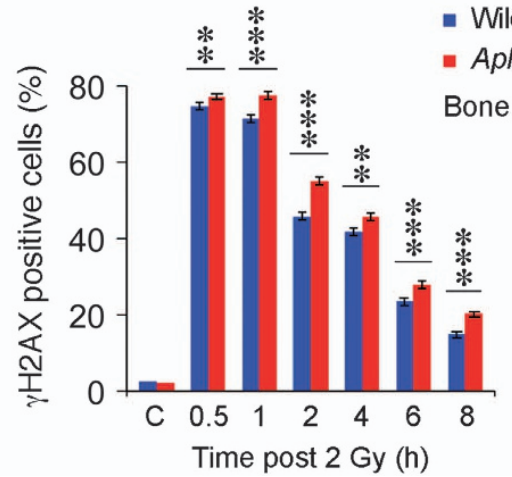

Figure $2 \mathrm{Aplf}^{-1-}$ mice have higher p53-mediated cell death and higher $\gamma \mathrm{H} 2 \mathrm{AX}$ positive damaged cells. (a) Percentage of live thymocytes $24 \mathrm{~h}$ after ionizing radiation (IR) (mean \pm S.D., normalized by non-irradiated controls; $n=3)$. Gy, Gray. ${ }^{*} P<0.05$; unpaired two-tailed Student's $t$-test. (b) TUNEL staining of thymi from mice $24 \mathrm{~h}$ after whole-body 6 Gy IR. Percentage of area that stained TUNEL (apoptosis) positive, as depicted, was quantified by ImageJ software. ${ }^{37}$ Scale bars, $500 \mu \mathrm{M}$. (c) Quantification of isolated bone marrow cells with ATM-mediated $\gamma \mathrm{H} 2 \mathrm{AX}$ (pS139) DNA damage signal at the indicated time after 2 Gy IR (mean \pm S.D.; $n=3$ ). C, non-irradiated control. ${ }^{*} P<0.05 ;{ }^{* *} P<0.01$; ${ }^{* *} P<0.001$; unpaired two-tailed Student's t-test elicit different outcomes including cell cycle arrest, DNA repair, apoptosis, and senescence, ${ }^{16,17}$ not all cells with DNA damage and DSBs will pass onto the next generation of cell cycle. Therefore, we also look into the magnitude of DSBs in dividing cells. By $8 \mathrm{~h}$ post IR, both wild type and $\mathrm{Ap}^{-f^{--}}$cells have already been released from IR-induced G2/M arrest and started to cycle normally (Figure $3 \mathrm{a}$ and Supplementary Figure S5). We found more bone marrow metaphases without chromosome or chromatid breaks in $A$ ff $^{-1-}$ than wild type $8 \mathrm{~h}$ post IR (11.3\% in WT versus $25.5 \%$ in Aplf $^{-1}$ ) (Figures 3b and $\mathrm{c}$ ). However, this phenotype was reverted by the simultaneous deletion of $p 53\left(9.5 \%\right.$ in $\left.\mathrm{Aplf}^{--} \mathrm{p53^{-- }}\right)$ demonstrating that p53-mediated cell death could efficiently eliminate damaged cells from transmitting DNA damage to the daughter cells (Figure $3 \mathrm{~b}$ ). By $24 \mathrm{~h}$ following IR, the proportion of undamaged cycling cells was comparable in all four genotypes (wild type, Aplf ${ }^{--}$, Aplf ${ }^{-1} p 53^{--}, p 53^{--}$) likely due to either DNA repair or clearance by cell death (Figure 3b). Since DNA damage can be repaired faithfully or unfaithfully, we therefore evaluated the extent of chromosomal aberrations after the induction of a large amount of DSBs by IR. Early evasion of damaged cells in $\mathrm{Ap}^{-f^{--}}$mice by the p53-mediated cell death pathway led to a lower translocation incidence than in wild type $(20.8 \%$ in WT versus 8.3\% in $\mathrm{Aplf}^{-1}$ ) (Figures 3d and e). Indeed, bone marrow metaphases from $A p l f^{-1} p 53^{--}$and $p 53^{-1}$ mice, in which the p53-dependent cell death function was impaired, had higher IR-induced chromosomal translocations (35\% in $\mathrm{Aplf}^{-1} \mathrm{p53^{-1 }}$ and $42.6 \%$ in $p 53^{-1}$ ) than metaphases from either wild type or $A p / f^{-1-}$ mice. These data demonstrate the important role of p53 in the reduction of IR-induced translocation in $\mathrm{Aplf}^{-/}$ cells following irradiation.

Depletion of APLF also reduces radiation-associated chromosomal aberration in human non-tumorigenic MCF10A cells. We attempted to examine if loss of APLF would similarly reduce the risk of chromosomal abnormalities in human cells. We knocked down APLF (APLF-KD) in the non-tumorigenic MCF10A human breast cell line by siRNA (Figure 4a). One day after exposure to 2 Gy, APLF-KD MCF10A cells had significant attenuation of chromosomal translocation and increased apoptosis compared with the non-targeting siRNA controls (Figures $4 b-g$ and Supplementary Figures S9C and D). Therefore, like Aplf ${ }^{-1-}$ mice, depletion of APLF in human cells lowered the risk of IRinduced chromosomal abnormalities.

IR-treated Aplf ${ }^{-1}$ mice have less clonal chromosomal translocations in bone marrow 5 months after IR. We exposed animals to a small dose of whole-body irradiation at 50 milliGray (mGy) followed by a higher dose of 6 Gy after a 48-h interval to reduce radiation toxicity to normal tissues (Figure 5a). ${ }^{19,20}$ Aplf $^{-1}$ mice invariably showed overall higher rates of p53-mediated cell death compared with wild-type mice (86.4\% live cells in WT, $70.8 \%$ live cells in Aplf $^{--}$), while the simultaneous disruption of p53 in $A p l f^{--}$mice (Aplf ${ }^{-1}$ $p 53^{-1}$ ) rescued the IR-induced cell death phenotype (Figure 5b). Not all cells with chromosomal translocations will survive and propagate over time. Cells with clonal translocations, which are able to expand, have likely acquired 


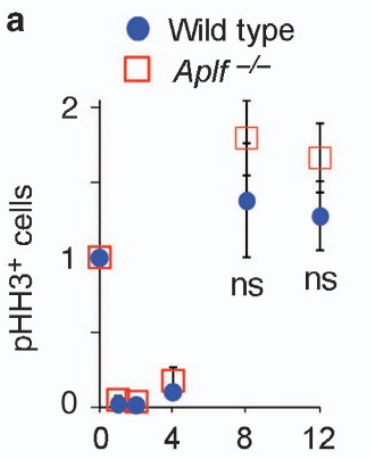

TIme post 2 Gy (h) b

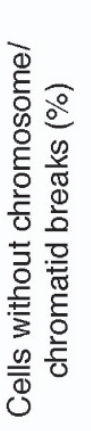

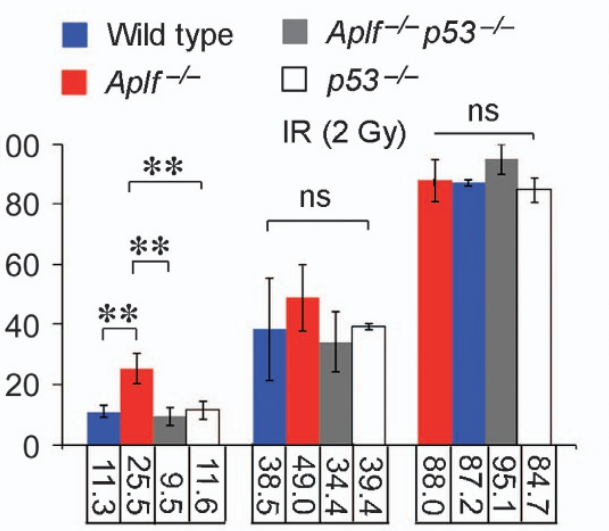

$8 \mathrm{~h}$

$24 \mathrm{~h}$

NIR

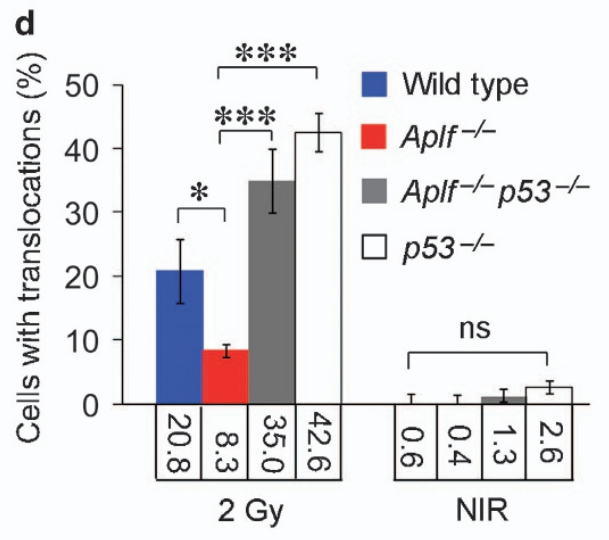

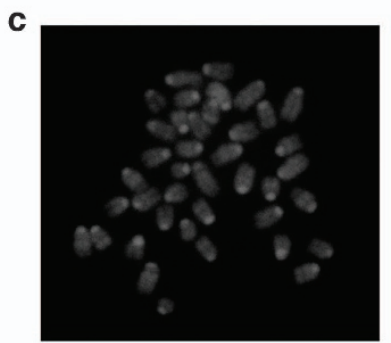
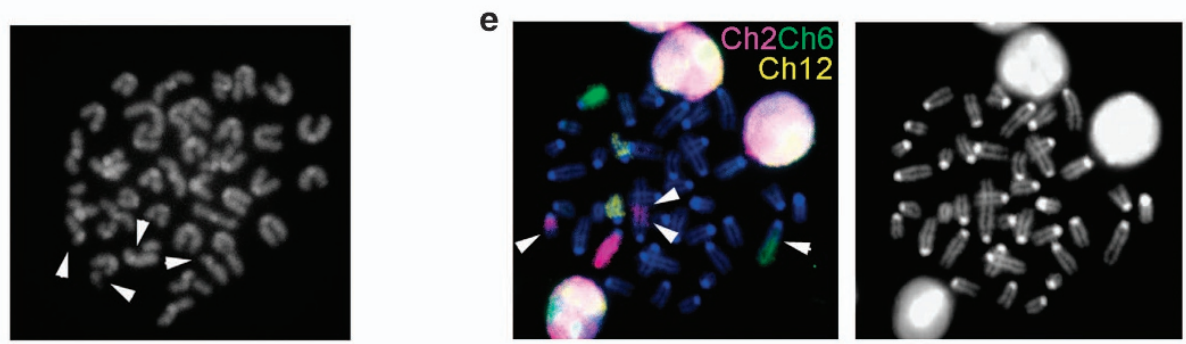

Figure 3 Wild-type and Aplf ${ }^{--}$mice recovered similarly from IR-induced G2/M arrest but $A$ plf ${ }^{-1}$ mice have less dividing cells with DNA damage and less IR-induced chromosomal translocation in the bone marrow. (a) The extent of the mitotic (M) phase was measured as the amount of phosphorylated histone H3 (pHH3, Ser10)-positive cells by flow cytometry and normalized by untreated controls. Data shown are mean \pm S.D. of four mice per group. NS, not significant. (b) Percentage of undamaged metaphases of non-irradiated (NIR) and irradiated (2 Gy) bone marrow cells 8 or $24 \mathrm{~h}$ after IR. At least 50 metaphases from each mouse were randomly picked and scored (mean \pm S.D.; $n=3$ mice per group). ${ }^{*} P<0.05 ;{ }^{* *} P<0.01 ;{ }^{* * *} P<0.001$; one-way ANOVA with Tukey's post hoc test. NS, not significant. (c) Example of undamaged cell (left) and cell with DSBs (arrowhead, right) ( $\times 630$ magnification). (d) Percentage of bone marrow metaphases carrying chromosomal translocations $24 \mathrm{~h}$ after 2 Gy IR. At least 50 metaphases from each mouse were randomly picked and scored (mean \pm S.D.; $n=3$ mice per group) ${ }^{*} P<0.05 ;{ }^{* \star} P<0.01$; ${ }^{* *} P<0.001$; one-way ANOVA with Tukey's post hoc test. NS, not significant. (e) An example of a cell with translocations (arrowheads, left) and DAPI stain of the same metaphase (right), chromosomes 2 (red), 6 (green), and 12 (yellow) (x630 magnification)

survival and proliferative advantages. Therefore, we also looked into the long-term effects of IR on the animals. Five months after radiation exposure, wild-type mice had two- to fivefold higher mean chromosomal translocation rates than those of the $\mathrm{Aplf}^{-/}$ mice (Figure 5c). Most samples showed complex karyotypes. In particular, irradiated wild-type mice had one or more prominent clonal chromosomal rearrangements ranged from 30 to $70 \%$ in frequency, while those in $A$ plf $f^{-1}$ mice were fewer with a frequency of $25 \%$ or lower (Figures $5 d-f$ ).

Reduced C-NHEJ capacity in Aplf $^{-1-}$ mice delays IRinduced dysplasia in hematopoietic cells and malignancyrelated mortality. To examine the impact of reduced NHEJ activity on therapy-related carcinogenesis, we monitored mouse cohorts exposed to $50 \mathrm{mGy}$ followed by $6 \mathrm{~Gy}$ after $48 \mathrm{~h}$. Irradiated wild-type mice began to develop IR-induced malignancy and died starting approximately 150 days after IR treatment (Figures 6a and b and Supplementary Figures S6 and S7). Conversely, Aplf ${ }^{-1}$ mice, which showed higher IR-induced cell death (Figures $2 \mathrm{a}, \mathrm{b}$ and $5 \mathrm{~b}$, and Supplementary Figure S9A) and lower chromosomal translocations (Figure 3d), had no malignancy-induced mortality more than 400 days post IR exposure (Figures $6 a$ and b and Supplementary Figures S6 and S7). The survival was significantly shortened by the simultaneous deficiency of p53 on an Aplf null background $\left(A p / f^{--} p 53^{--}\right.$) (Figure $6 \mathrm{~b}$ and Supplementary Figures $\mathrm{S} 7$ and S8A), which demonstrated high translocation frequency after IR (Figure 3d). Myeloid neoplasms resembling myeloid dysplasia ${ }^{21}$ were observed in these moribund or deceased irradiated wild type, $A p l f^{-1} p 53^{-1-}$, and $p 53^{-1}$ animals. Of note, apart from about $30 \%$ of the irradiated $\mathrm{Aplf}^{-1} \mathrm{p53^{-1 }}$ and $p 53^{-1}$ mice that died immediately from thymic lymphoma, reminiscent of $p 53^{-1-}$ mice (Figure $6 \mathrm{~b}$ and Supplementary Figure S8B), ${ }^{22}$ there was no development of thymic lymphoma identified in the necropsies from the rest of the IR-treated wild type, $A p l f^{-\alpha} p 53^{-1-}$, and $p 53^{-\alpha}$ mice examined. These affected wild type, Aplf ${ }^{-1-} p 53^{-1-}$, and $p 53^{-1-}$ mice had either hypo- or hyper-cellular bone marrow (Figure 6c). Excessive proliferation of myeloblasts was not observed. In contrast, these animals showed abnormal hematopoiesis in peripheral blood and bone marrow, including hypersegmentation in granulocytes; Howell-Jolly bodies, polychromasia, and poikilocytosis in erythrocytes; binucleated erythroblasts; and dysplastic megakaryocytes with hypolobated nuclei or multiple separate nuclear lobes (Figures $6 \mathrm{~d}-\mathrm{g}$ ). These features are consistent with single- and multi-lineage dysplasia and anemic conditions of human MDS or t-MDS. A case of neutropenia was also noted. 
a

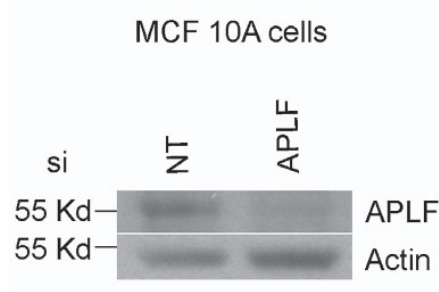

b

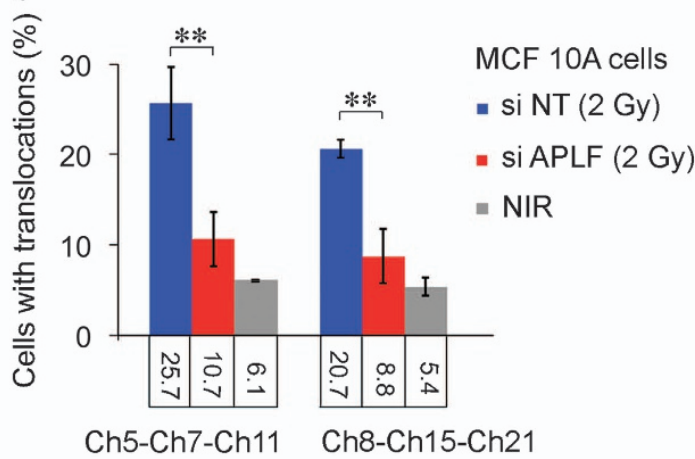

C

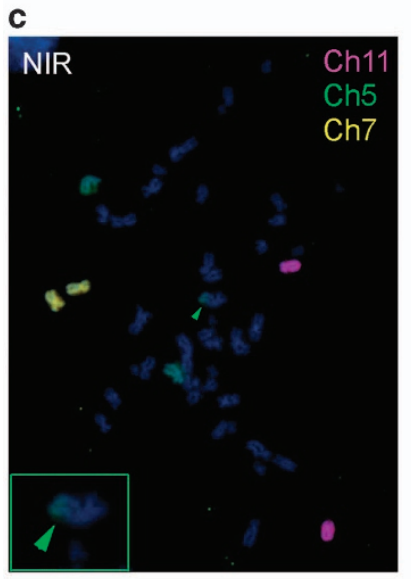

f

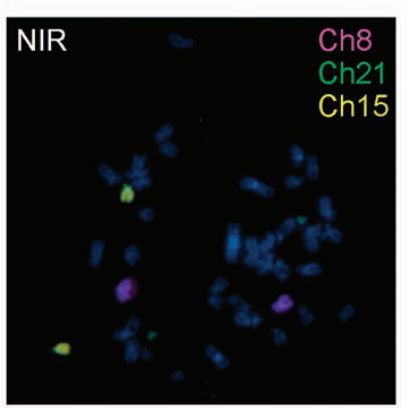

d

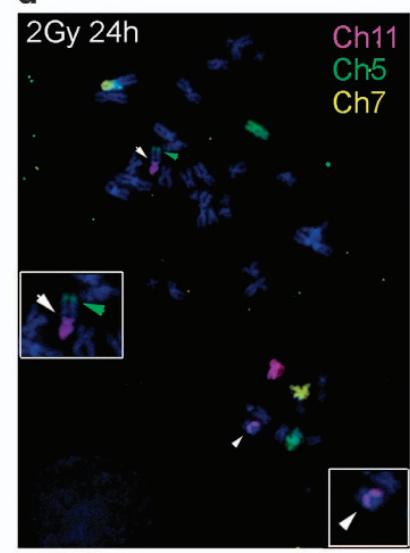

e

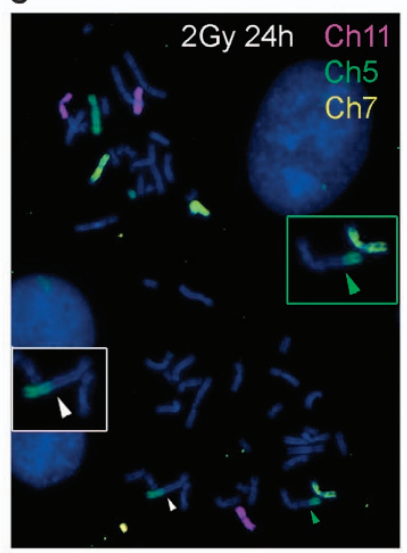

g

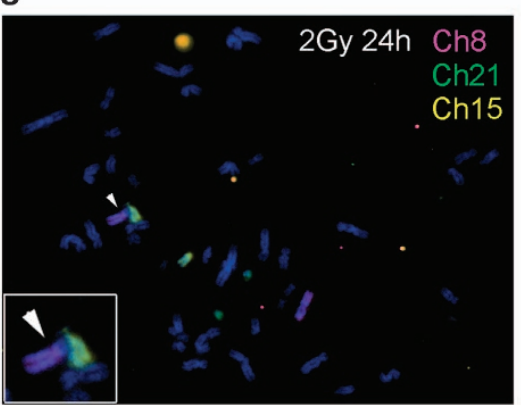

Figure 4 siRNA knockdown of APLF also reduced translocations in irradiated human non-tumorigenic MCF10A cell line. (a) Western blot showing the APLF protein level after 48-h treatment with a mixture of four siRNAs (Dharmacon) against APLF or a mixture of non-targeting negative siRNA control pool, which have been designed and microarray tested for minimal targeting of human, mouse, or rat genes (NT). (b) MCF10A cells were treated as described in (a) for $48 \mathrm{~h}$ before exposure to $2 \mathrm{~Gy}$ IR. Percentage of metaphases carrying chromosomal translocations of chromosomes 5, 7, or 11 (Ch5-Ch7-Ch11) and chromosomes 8, 15, or 21 (Ch8-Ch15-Ch21) was scored 24 h after irradiation. Fifty metaphases of each independent experiment were randomly picked and scored (mean \pm S.D.; $n=3$ independent experiments for each treatment type) ${ }^{* *} P<0.01$. (c-e) Photomicrographs showing examples of chromosomal translocations and abnormalities in non-irradiated control (NIR, $\left.\mathbf{c}\right)$ and irradiated (2 Gy; $\mathbf{d}$ and $\left.\mathbf{e}\right)$ MCF10A cells for chromosomes 11 (red), 5 (green), and 7 (yellow). Green arrowhead depicts a background translocation that involves chromosome 5 found in MCF10A cell line in (c-e). This background translocation was not scored as IR-induced aberration (white arrowheads) and was excluded when evaluating translocation frequency described in (b). Insets are expanded views of the abnormal chromosomes found in each metaphase displayed. DNA was stained by DAPI, blue. (f and $\mathbf{g}$ ) Photomicrographs showing examples of chromosomal translocations and abnormalities in non-irradiated control (NIR, f) and irradiated (2 Gy, g) MCF10A cells for chromosomes 8 (red), 21 (green), and 15 (yellow)

IR-treated moribund wild-type mice have oncogenic clonal chromosomal aberrations. We examined an IRtreated moribund wild-type mouse cytogenetically and found complex chromosomal rearrangements of $t(9 ; 11), t(Y ; 16)$ del (13), and $t(2 ; 16)$ del(8) (Figure $7 a)$. The $t(9 ; 11)$ clone, both in the spleen and the bone marrow (Figures $7 \mathrm{~b}-\mathrm{g}$ ), showed a single copy deletion of the Hoxb gene cluster and translocations of both Rara and the oncogene Ets1. Downregulation of either $H O X B 1^{23}$ or $H O X B 9^{24}$ has been previously observed in a number of human AML cell lines and patient samples; hence, their functional roles in the proper differentiation of the myeloid lineage have been proposed. Chromosomal rearrangements of the $R A R A^{25}$ or the $E T S 1^{26}$ locus have also been reported in patients with myeloid neoplasms. 
a

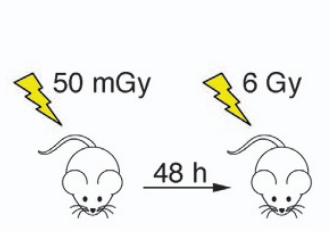

Two months old b

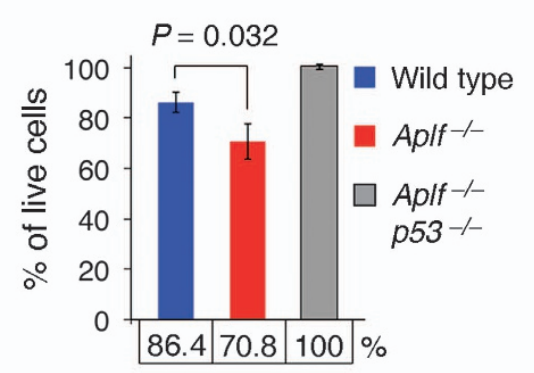

c

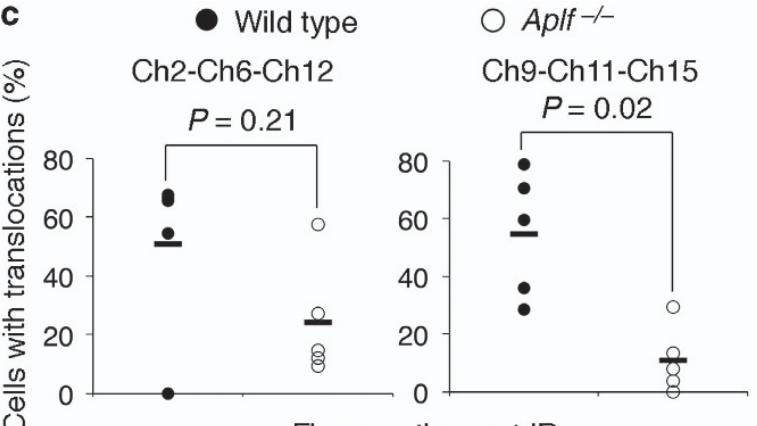

Five months post IR

f

d Clonal translocations in bone marrow 5 months post IR

\begin{tabular}{|c|c|c|c|c|c|}
\hline WT 1 & & WT 2 & WT 3 & WT 4 & WT 5 \\
\hline \multirow[t]{4}{*}{$0 \%$} & \multicolumn{2}{|c|}{$t(2 ; U) t(6 ; U)[40.6 \%]$} & $\begin{array}{c}\operatorname{Der}(12) t(12 ; U) \\
{[63.6 \%]}\end{array}$ & $\mathrm{t}(6 ; 12)[33.3 \%]$ & $\mathrm{t}(2 ; U)[67.7 \%]$ \\
\hline & \multicolumn{2}{|c|}{$\operatorname{Der}(2) t(2 ; U)[15.6 \%]$} & $\begin{array}{c}\operatorname{Der}(6) t(6 ; U) \\
{[3.0 \%]}\end{array}$ & $\mathrm{t}(12 ; U)[9.1 \%]$ & \\
\hline & \multicolumn{2}{|r|}{$\mathrm{t}(6 ; \mathrm{U})[6.3 \%]$} & & $\begin{array}{c}\operatorname{Der}(6) t(6 ; U) \\
{[6.1 \%]}\end{array}$ & \\
\hline & \multicolumn{2}{|c|}{$\operatorname{Der}(12) t(12 ; U)[3.1 \%]$} & & $\mathrm{t}(2 ; \mathrm{U})[3.0 \%]$ & \\
\hline $0 \%$ & & $65.6 \%$ & $66.6 \%$ & $51.55 \%$ & $67.7 \%$ \\
\hline \multicolumn{2}{|c|}{ WT 1 } & WT 2 & WT 3 & WT 4 & WT 5 \\
\hline \multirow{4}{*}{\multicolumn{2}{|c|}{$\begin{array}{c}\operatorname{Der}(9) t(9 ; U) \\
{[59.6 \%]} \\
\end{array}$}} & $\begin{array}{c}\operatorname{Der}(9) \mathrm{t}(9 ; \mathrm{U}) \\
\mathrm{t}(9 ; 11 ; \mathrm{U})[71.2 \%]\end{array}$ & $\begin{array}{c}\operatorname{Der}(15) t(15 ; U) \\
{[70.6 \%]}\end{array}$ & $\begin{array}{c}\mathrm{t}(9 ; \mathrm{U}) \\
{[14.3 \%]}\end{array}$ & $\mathrm{Rb}(15 . \mathrm{U})[30 \%]$ \\
\hline & & $\begin{array}{c}\mathrm{t}(9 ; 11: U), \mathrm{t}(15 ; \mathrm{U}) \\
{[3.8 \%]}\end{array}$ & & $\begin{array}{l}t(11: U) \\
{[12.2 \%]}\end{array}$ & $\mathrm{t}(11 ; 15)[2 \%]$ \\
\hline & & $\mathrm{t}(9 ; \mathrm{U})[1.9 \%]$ & & $\begin{array}{c}\mathrm{t}(9 ; \mathrm{U}), \mathrm{t}(11: \mathrm{U}) \\
{[2.0 \%]}\end{array}$ & $t(9: U)[2 \%]$ \\
\hline & & $\begin{array}{c}\operatorname{Der}(15) t(15: U) \\
{[1.9 \%]}\end{array}$ & & & $t(11: U)[2 \%]$ \\
\hline 59. & & $78.8 \%$ & $70.6 \%$ & $28.5 \%$ & $36 \%$ \\
\hline
\end{tabular}

。

\begin{tabular}{|c|c|c|c|c|c|}
\hline KO 1 & KO 2 & KO 3 & $\mathrm{KO} 4$ & \multicolumn{2}{|c|}{ KO5 } \\
\hline $\mathrm{t}(6 ; \mathrm{U})[6.1 \%]$ & $\begin{array}{c}\operatorname{Der}(6) t(6 ; U) \\
\operatorname{der}(12) t(12 ; U) \\
{[15.2 \%]}\end{array}$ & $\begin{array}{c}\operatorname{Der}(12) t(12 ; U) \\
{[24.2 \%]}\end{array}$ & $\begin{array}{c}t(2 ; U), t(6 ; U) \\
{[6.3 \%]}\end{array}$ & \multicolumn{2}{|c|}{$\begin{array}{c}\operatorname{Der}(2) t(2 ; U) \\
{[14.7 \%]}\end{array}$} \\
\hline $\begin{array}{c}t(2 ; U), t(6 ; U) \\
\operatorname{der}(12) t(12 ; U) \\
{[3.0 \%]} \\
\end{array}$ & $t(2 ; U)[15.2 \%]$ & $\mathrm{t}(2 ; \mathrm{U})[3.0 \%]$ & $\begin{array}{c}\mathrm{t}(2 ; \mathrm{U}), \mathrm{t}(6 ; \mathrm{U}) \\
\operatorname{der}(12) \mathrm{t}(12 ; \mathrm{U}) \\
{[3.1 \%]}\end{array}$ & & \\
\hline \multirow[t]{3}{*}{$\begin{array}{c}\operatorname{Der}(12) t(12 ; U) \\
{[3.0 \%]} \\
\end{array}$} & $\begin{array}{c}\operatorname{Der}(6) t(6 ; U) \\
{[15.2 \%]}\end{array}$ & & & & \\
\hline & $\begin{array}{l}\operatorname{Der}(2) \mathrm{t}(2 ; \mathrm{U}) \\
\mathrm{t}(6 ; \mathrm{U})[9.1 \%]\end{array}$ & & & & \\
\hline & $\begin{array}{c}\operatorname{Der}(12) t(12 ; U) \\
{[3.0 \%]}\end{array}$ & & & & \\
\hline $12.1 \%$ & $57.7 \%$ & $27.2 \%$ & $9.4 \%$ & & $4.7 \%$ \\
\hline KO 1 & $\mathrm{KO} 2$ & $\mathrm{KO} 3$ & \multicolumn{2}{|c|}{$\mathrm{KO} 4$} & KO 5 \\
\hline$t(11: U)[3.8 \%]$ & $\mathrm{t}(9: U)[9.6 \%]$ & $\mathrm{t}(11 ; \mathrm{U})[8 \%]$ & \multicolumn{2}{|c|}{$\begin{array}{c}\operatorname{Der}(9) t(9 ; U) \\
\operatorname{der}(11) t(11 ; U) \\
{[23.5 \%]} \\
\end{array}$} & $0 \%$ \\
\hline & $\mathrm{t}(11 ; U)[3.9 \%]$ & & \multicolumn{2}{|c|}{$\operatorname{Der}(9) t(9 ; \cup)[5.9 \%]$} & \\
\hline $3.8 \%$ & $13.5 \%$ & $8 \%$ & \multicolumn{2}{|c|}{$29.4 \%$} & $0 \%$ \\
\hline
\end{tabular}

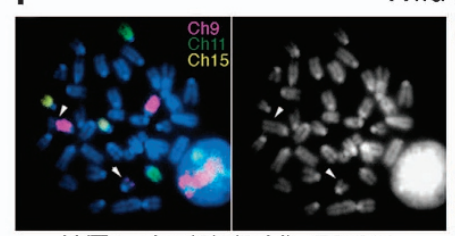

WT1, der(9)t(9;U), 59.6\%

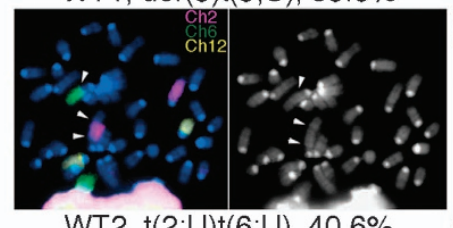

WT2, t(2;U)t(6;U), $40.6 \%$

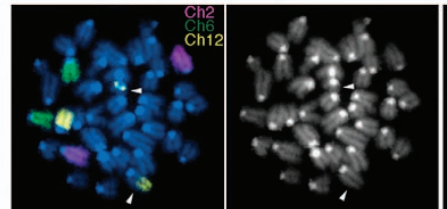

WT3, der(12)t(12;U), 63.6\%
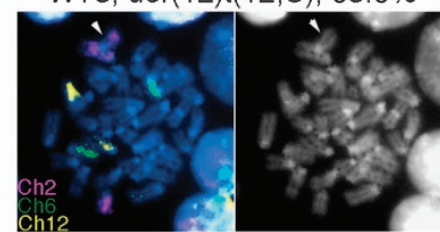

WT5, t(2;U), $67.7 \%$

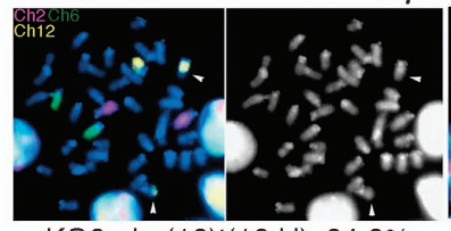

KO3, der(12)t(12;U), $24.2 \%$

Wild type

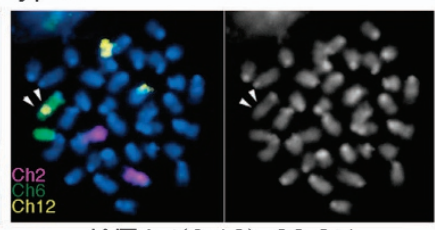

WT4, t(6;12), 33.3\%

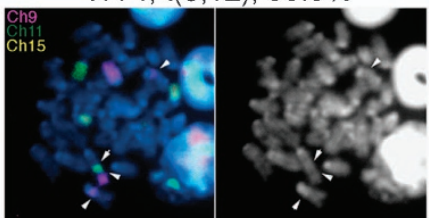

WT2, $\operatorname{der}(9) \mathrm{t}(9 ; \mathrm{U}), \mathrm{t}(9 ; 11 ; \mathrm{U}), 71.2 \%$

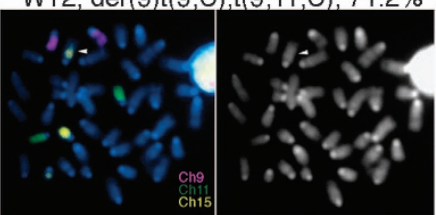

WT3, der(15)t(15;U), $70.6 \%$

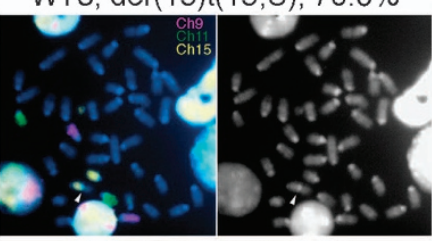

WT5, Rb(15.U), 30\%

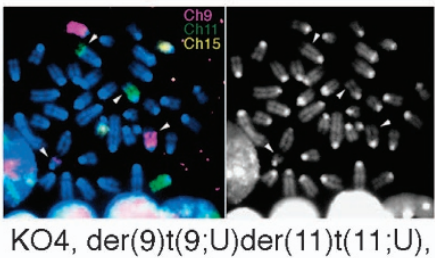

$23.5 \%$

Figure 5 IR-treated Aplf $f^{-1}$ mice have less clonal chromosomal translocations in bone marrow 5 months after IR. (a) Irradiation strategy. (b) Percentage of live thymocytes $24 \mathrm{~h}$ after whole-body $\gamma$-irradiation treated as described in (a) (mean \pm S.D., normalized by untreated controls; $n=3$ ). The $P$-values were derived from unpaired two-tailed Student's $t$-test. (c) Mice were irradiated as described in (a), and bone marrow cells were isolated five months post IR. Percentage of bone marrow cells with translocations involving chromosomes 2, 6, 12 (left) or chromosomes 9, 11, 15 (right). Each circle (open or closed) represents the frequency of cell with translocations by scoring at least 30 metaphases per mouse. Horizontal bar is the mean of five mice. The $P$-values were derived from two-tailed Mann-Whitney test. (d) The distribution of clonal translocations involving chromosomes 2, 6, 12 (top) or chromosomes 9, 11, 15 (bottom) in the irradiated wild-type mice as described in (c). Total percentage of translocation for each three-color chromosome panel per mouse is depicted at the bottom. t, translocation; ( ), type of chromosomal translocations; [ ], percentage of the described translocation; Der, derivative; Rb, Robertsonian translocation; $U$, chromosome other than chromosomes 2, 6, 12 for top panel or other than chromosomes 9, 11, 15 for bottom panel. (e) The distribution of clonal translocations in irradiated $\mathrm{Aplf}^{-1-}$ mice as described in (c and d). (f) Photomicrographs depict representative prominent clonal translocations in the bone marrow 5 months after IR as described in (c-e). Percentage of each clone is as indicated in parenthesis and only images of clones that accumulate $25 \%$ and above are shown. White arrowheads indicate the breakpoints in the rearranged chromosomes 


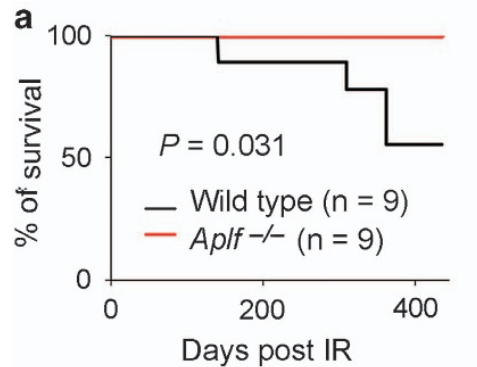

(C57BL/6J \& 129/Ola mixed)

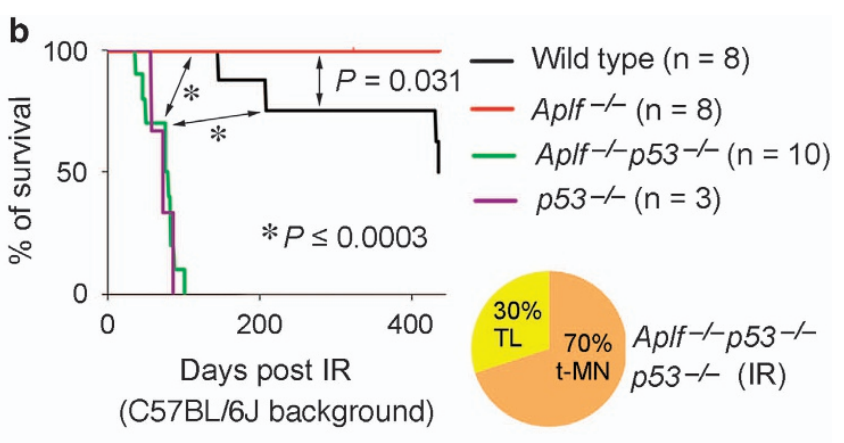

(C57BL/6J background)
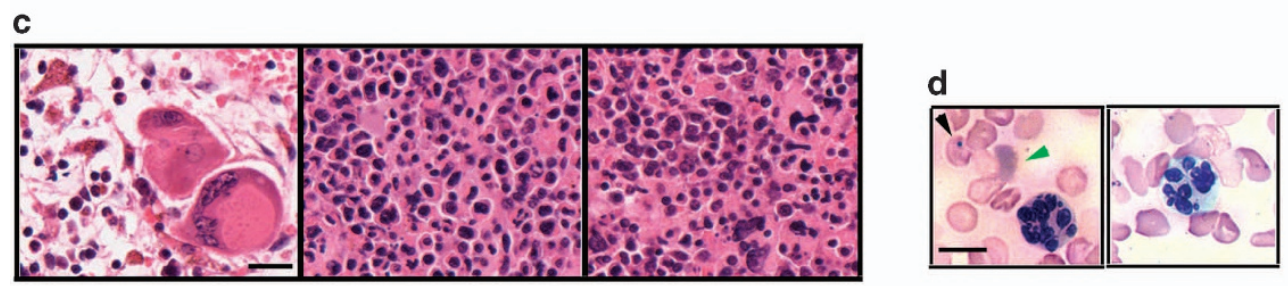

e
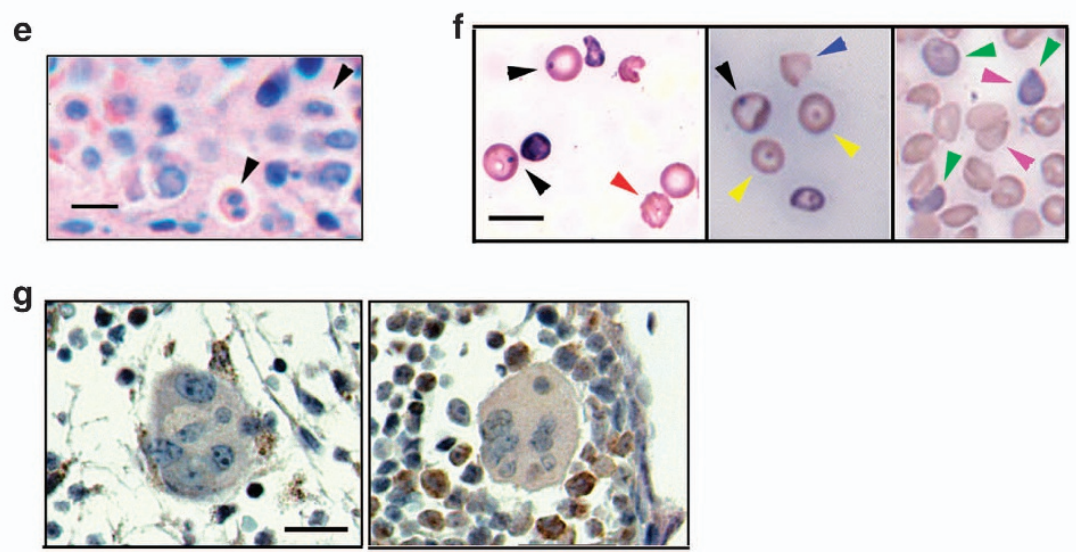

Figure 6 APLF deficiency delays IR-induced dysplasia in hematopoietic cells and malignancy-related mortality. (a) The Kaplan-Meier survival curve for mice of C57BL/6J and 129/Ola mix background irradiated as described in Figure 5a. The $P$-value was derived from log-rank test. (b) The Kaplan-Meier survival curve for mice of C57BL/6J background irradiated as described in Figure 5a. P-values were derived from log-rank test. TL, thymic lymphoma; t-MN, therapy-related myeloid neoplasm. (c) Bone sections of irradiated sick mice stained by hematoxylin and eosin (H\&E). The left panel depicts a cluster of dysplastic megakaryocytes in the hypocellular bone marrow. Middle and right panels depict the hypercellular bone marrow. Scale bar, $20 \mu \mathrm{M}$. (d) Dysplastic hypersegmented neutrophils (granulocytes) in the peripheral blood (Wright's stain) of irradiated moribund mice were observed. Black arrowhead depicts Howell-Jolly body inclusion in erythrocyte and green arrowhead depicts a polychromatic erythrocyte. Scale bar, $10 \mu \mathrm{M}$. (e) The hypercellular bone marrow (Giemsa) displaying dysplastic binucleated erythroblasts (arrowheads). Scale bar, $10 \mu \mathrm{M}$. (f) Peripheral blood (Wright's stain) of irradiated sick mice showing abnormal erythrocytes with Howell-Jolly bodies (black arrowhead), echinocyte (red arrowhead), target cells (yellow arrowhead), shistocyte (blue arrowhead), polychromatic erythrocytes (green arrowhead) and teardrop erythrocytes (magenta arrowhead), indicating dyserythropoiesis and dysfunctional bone marrow or spleens. Scale bar, $10 \mu \mathrm{M}$. (g) Dysplastic megakaryocytes with multiple separate nuclear lobes were observed in irradiated sick mice with the hypocellular (left) or hypercellular (right) bone marrow stained by antimyeloperoxidase and hematoxylin. Scale bar, $20 \mu \mathrm{M}$

\section{Discussion}

In this present study, we found that APLF deficiency in mice modestly reduced DNA damage repair and NHEJ activity. APLF-depleted cells, both ex vivo and in vivo, exhibited higher rates of radiation-induced p53-dependent cell death (Figures 2 and $5 \mathrm{~b}$ ) and fewer chromosomal translocations (Figures 3 and 5c-f) following IR exposure. IR-treated mutant mice showed a delay in malignancy-induced mortality. Simultaneous deficiency of p53 dampened IR-induced apoptosis and have reverted the benefit of impaired DNA repair on mortality in irradiated APLF-deficient mice. Depletion of APLF in non-tumorigenic human cells also markedly reduced the frequency of radiation-induced chromosomal aberrations.
Mice with deficiencies of both C-NHEJ (XRCC4 or DNA ligase 4) and p53 had increased incidence of B-cell lymphomas associated with $c-m y c / l g H$ oncogenic translocations. The $c-m y c / l g H$ breakpoint junctions of more than $50 \%$ of tumors studied were made of short homology ( $\leq 3 \mathrm{nt})$, typical of C-NHEJ. ${ }^{27}$ In wild-type mouse B cells, C-NHEJ has been found to promote $c-m y c / l g H$ rearrangements with blunt and low microhomolgy (1-3 nt) at breakpoints. ${ }^{28}$ Recent reports showed that extensive microhomology-mediated joining ( $\geq 4 \mathrm{nt}$ ) at rearrangement breakpoints, one of the major features of $A-E J$, appears to be less frequent in de novo human translocations found in human cancer samples. ${ }^{29,30}$ An analysis of primary human prostate cancers showed that most chromosomal fusions in these patient cancer tissues 


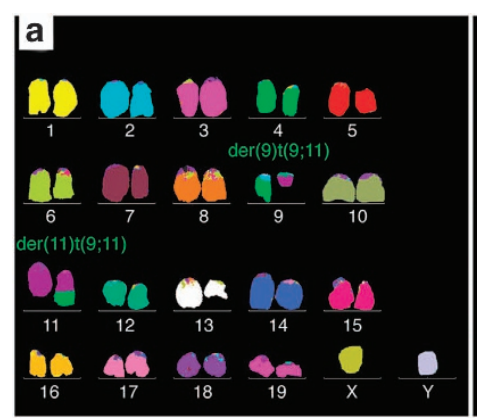

$\mathrm{t}(9 ; 11)$

(Normal Ch9) Ets1

\section{b}

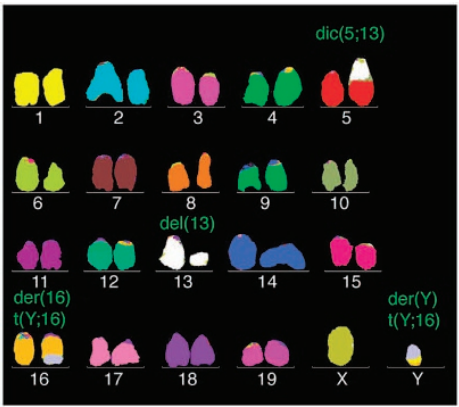

$t(Y ; 16) \operatorname{del}(13)$

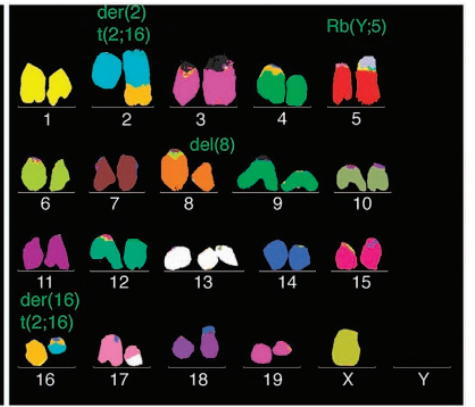

$\mathrm{t}(2 ; 16) \operatorname{del}(8)$

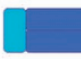

(Normal Ch11) Hoxb/Rara c

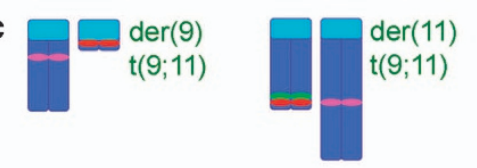

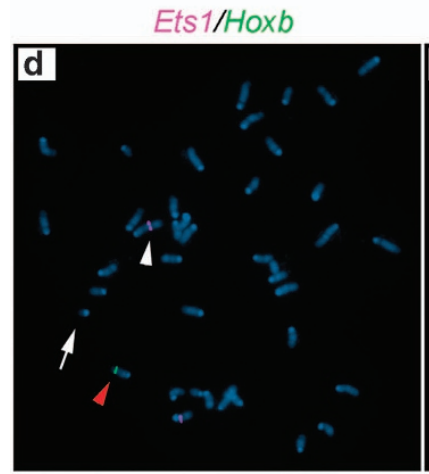
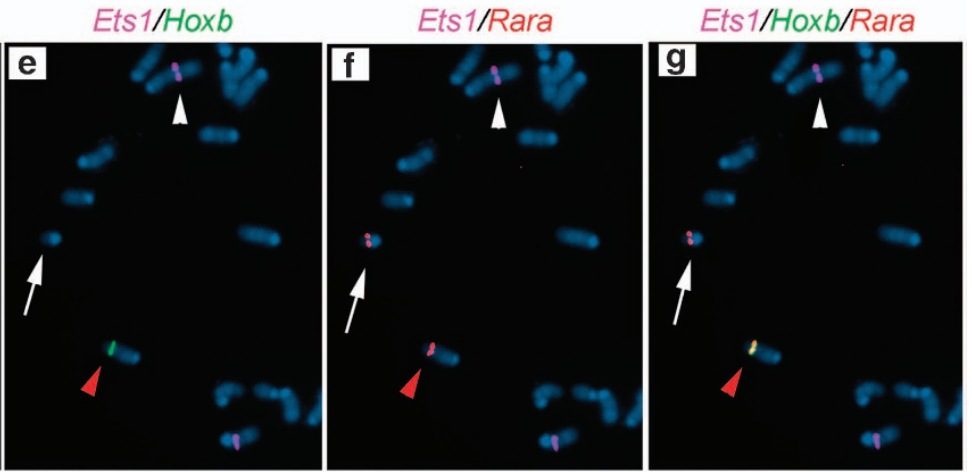

Figure 7 Oncogenic translocations and deletion found in irradiated moribund wild-type mouse. (a) M-FISH of spleen cells of a representative irradiated moribund wild-type mouse. Karyotypes of three clones of chromosomal abnormalities are shown (der, derivative; t, translocation; del, deletion; dic, dicentric chromosome; Rb, Robertsonian translocation). (b) Normal chromosomes 9 (Ch9) and 11 (Ch11) with indicated gene loci. (c) Cartoon for der(9)t(9;11) and der(11)t( $9 ; 11)$ rearranged chromosomes depicted in $(\mathbf{d}-\mathbf{g})$. (d-g) Two- and three-color FISH. The t(9;11) clonal translocation in (a, left) was verified by mouse BAC clones encompassing the locus of Hoxb gene cluster (green), Ets1 (pink), or Rara (red). (d) Photomicrograph showing the entire metaphase of the t(9;11) clonal translocation where only one copy of the Hoxb gene cluster (green) was observed in the single normal chromosome 11 (red arrowhead). (e-g) Photomicrographs showing enlarged views of (d) with the normal chromosome 11 carrying the Hoxb gene cluster (green, red arrowhead), derivative chromosome 9 [der(9)t(9;11)] (white arrow), and derivative chromosome 11 [der(11)t( $(9,11)]$ (white arrowhead)

involved direct joins at the rearrangement junctions. ${ }^{31}$ Other studies in human breast and pancreatic cancers revealed that the most frequent junctions involved 0-3 nt at rearrangement breakpoints. ${ }^{32,33}$ Our findings also showed higher rates of translocation in bone marrow cells of wild-type mice after exposure to IR, which was reduced by impairing C-NHEJ after knocking out Aplf. Depletion of APLF in the non-tumorigenic human breast cell line MCF10A also led to significant reduction of IR-induced chromosomal translocation. While genomic abnormalities in cancers are complex and diverse, the role of non-homologous end joining in somatic rearrangements is appreciated. ${ }^{29,30,32}$ The contribution of A-EJ to somatic translocations is still of particular interest since studies have showed an apparent interplay between C-NHEJ and A-EJ in modulating genome stability and translocations featuring longer microhomologies especially in cells lacking Ku or other core C-NHEJ factors. ${ }^{27,34-37}$

Deletion of genetic sequences is found frequently in cells from human patients. ${ }^{29,30,33}$ We also detected both translocations and deletion of gene clusters after chromosomal rearrangement in irradiated wild-type mice and human non-tumorigenic MCF10A cells. Loss of part or all of chromosomes $5(5 q-1-5)$ and/or 7 (7q-l-7), complex cytogenetics, and a poor response to chemotherapy are characteristic findings in t-MN patients. ${ }^{38}$ Mutations found in t-MN patients include those observed in patients with de novo MDS and AML: FLT3, CKIT, PTPN11, NRAS, RAS, BRAF, c-FMS, JAK2, CEBPA, TP53, and AML1 genes. ${ }^{39}$ Previous studies suggest that about $30 \%$ of t-MN patient carry loss-of-function mutations in TP53. ${ }^{4,38} \mathrm{~A}$ recent study indicates that the high frequency of TP53 mutations in t-MN patients may not be directly induced by genotoxic treatments. But, rather, when there are age-related loss-of-function mutations of TP53 in rare hematopoietic stem/progenitor cells, these cells may become resistant to chemo- and radiotherapies and hence can preferentially expand even after treatment. ${ }^{4}$ Another rational explanation, as demonstrated by the present study, is that when the p53-mediated cell death pathway is impaired due to mutations in TP53, instead of clearing away severely damaged cells, more cells carrying DNA DSBs will survive and are repaired by the C-NHEJ pathway faithfully and unfaithfully. Therefore, mutations in TP53are frequent in t-MN patients and 
are associated with the higher risk of chromosomal abnormality formation and malignant transformation after genotoxic therapies.

$\mathrm{Li}$ et al. have generated mice bearing lysine to arginine mutations at the acetylation sites in p53. These mutations did not affect the metabolic regulation and antioxidant function of p53 but seemed sufficient for inhibiting early-onset spontaneous thymic lymphoma usually found in p53 null mice. ${ }^{22,40}$ Cellular DNA damages trigger a spectrum of signaling which leads to the stabilization of p53, ATM/ATR-associated direct phosphorylation of Ser18 of p53 in mice (Ser15 in human p53) and ATM/ATR-associated indirect phosphorylation of Ser23 of p53 in mice (Ser20 in human p53) via chk2 protein kinase. $^{16,17}$ Mice that harbor alanine substitutions of these two key DNA damage-targeted phosphorylation sites of Ser18 and Ser23 in p53 are resistant to IR-induced p53-dependent apoptosis. These alanine substituted p53 mutant mice developed an array of malignancies, thereby reinforcing a link between p53-dependent DDRs and tumor suppression. ${ }^{41}$ Another study also showed that mice with a single alanine substitution at Ser18 of p53, instead of developing early-onset spontaneous tumors like those found in p53 null mice, were succumbed to late-onset lymphomas, demonstrating that DDR function of p53 is important to tumor suppression in vivo. ${ }^{42}$

The current study demonstrates that the C-NHEJ pathway plays a role in producing genomic abnormalities in particular following the induction of a large number of DSBs from genotoxic treatments. We conclude that the more error-prone NHEJ DNA damage repair, even when the classical NHEJ pathway predominates, can promote genomic instability in normal tissues after genotoxic therapies. Carcinogenesis can be driven by complex chromosomal rearrangements, deletions or mutations. Manipulation of the efficiency in DNA damage repair may have the potential to intervene in the development of these diseases.

Genotoxic therapy-induced cell death is the common rationale behind most cancer therapies. This approach needs to be balanced against the risk of therapy-induced acute and late toxic side effects in normal tissues, such as anemia, fibrosis, and second cancers, which may limit the efficacy of therapy that can be administered to patients. ${ }^{43}$ This is an important area of investigation that warrants further exploration in future studies. Central to this notion is whether sensitizing TP53 during cancer therapies augments therapyrelated toxicity. The present study demonstrates that one of the most serious and deadly therapy-induced toxic side effects, second cancers, could potentially be reduced. Indeed, the balance of excessive cell death and evasion of damaged cells need to be carefully controlled to maximize the benefits of TP53 as the guardian of genome.

\section{Materials and Methods}

Antibodies and reagents. Anti-mouse B220 (Clone RA3-6B2), CD43 (Clone eBioR2/60), IgM (Clone II/41), CD3 (Clone 145-2C11), CD4 (Clone RM4-5), CD8 (Clone 53-6.7) and 7-amino-actinomycin D (7-AAD) were obtained from eBioscience (San Diego, CA, USA). Anti-mouse lgG1 (Clone A85-1), $\alpha \beta T C R$, Streptavidin Particles Plus-DM, and Annexin V-FITC were from BD Biosciences (San Jose, CA, USA). APLF antibody ( $\mathrm{N}-16)$ and actin antibody (C-11) were from Santa Cruz (Dallas, TX, USA). Recombinant murine interleukin 4 (IL-4), IL-3, IL-6,
Flt3-ligand, stem cell factor (SCF), TPO, and recombinant human TSLP were from Peprotech (Rocky Hill, NJ, USA), lipopolysaccharides (LPS) from Sigma (Oakville, ON, Canada), propidium iodide (PI) from Invitrogen (Waltham, MA, USA), and red blood cell lysing buffer from Sigma.

Gene-targeted deletion of murine Aplf locus. The targeting construct was designed to replace exons 2-3 of Aplf by PGK promoter-driven neomycin resistance gene, which would create frameshift mutation starting within the Forkhead associated domain. Targeting vector was linearized by Notl digestion and electroporated into E14K embryonic stem (ES) cells (129/Ola). G418-resistant ES cell clones were then screened for homologous recombination by nested PCR. Candidate ES cells clones were further confirmed by Southern blot with PCR-generated probes (1 and 2) as described in Supplementary Figure S1A, using the standard method. Four correctly targeted clones were confirmed and three were injected into C57BL/6J blastocysts. Two independent mouse lines were successfully established using standard procedures.

Southern blot analysis. Genomic DNA was extracted from the indicated ES cell clones. BamHI-digested DNA was resolved by electrophoresis, transferred onto nitrocellulose membrane, and hybridized by ${ }^{32} \mathrm{P}$ radioactive probes using the standard method as described in the legend of Supplementary Figure S1A. Probed membranes were exposed to storage phosphor screen (Perkin Elmer, Waltham, MA, USA). Images were captured by the Typhoon Trio Imager (GE Healthcare, Chicago, IL, USA).

Primers. Aplf ${ }^{-1}$ mice were genotyped using following primers: (2637U) $5^{\prime}$-CTTA CTGGGCTTGACTTTAGAC-3'; (3570) 5'-GGCTTGATTCGAAGCTGACTAT-3'; and (2995L) 5'-CATCGCCTTCTATCGCCTTCTT- $3^{\prime}$ as primers a, b, c described in Extended Data Figure S1a. The following primers were used for the semiquantitative PCR: Aplf, forward $5^{\prime}$-GAATCAAGCCAATCCATAGGAATC- ${ }^{\prime}$ and reverse 5'-CATCTGACTGTTTCTCAGAGTAC-3'. The following primers were used for qRT-PCR: Puma forward $5^{\prime}$-CTGGAGGGTCATGTACAATCTCTT-3' and reverse 5'-CACCTAGTTGGGCTCCATTTCT-3'; mdm2, forward 5'-GGATCTTGACGATGGC GTAAG-3' and reverse 5'-AGGCTGTAATCTTCCGAGTCC-3'; APLF1, forward 5'-CCGCTGCTGGGAATAACAGA-3' and reverse 5'-GCTTCAATGGTAAGAGCTG ACT-3'; APLF2, forward 5'-CAGCTCTTACCATTGAAGCCA-3' and reverse 5'-CCA GTTGTGAGGCACCAGTAG-3' primers.

Animal studies. Procedures for maintaining mice and all experiments described were approved by the Ontario Cancer Institute Animal Facility and were performed in compliance with the regulations of the Animal Ethics and Animal Care Committees at the Princess Margaret Cancer Centre. Unless indicated in the figure legends, $\mathrm{Aplf}^{1-}$ mice used in the analyses have been backcrossed with C57BL/6J mice for six generations. $p 53^{+/-}$mouse was purchased from Taconic. Atm-knockout mouse $^{44}$ was generated by Peter J McKinnon (St. Jude Children's Research Hospital, Memphis, TN, USA) and kindly provided by Tak W Mak (Ontario Cancer Institute, Toronto, ON, Canada). The backcrossed $\mathrm{Aplf}^{-1}$ mice were used to generate $\mathrm{Aplf}^{--} \mathrm{Atm}^{--}$and $\mathrm{Aplf}{ }^{--} \mathrm{p}^{-1} 3^{--}$mice by mating $\mathrm{Aplf}^{--}$mice with $\mathrm{Atm}^{+-}$or $p 53^{+/}$, respectively. For mouse cohort studies, mice of 2 months old were exposed firstly to $50 \mathrm{mGy}$ (at $28.84 \mathrm{cGy} / \mathrm{min}$ ) of irradiation, followed by 6 Gy (at $108.25 \mathrm{cGy} /$ $\mathrm{min}$ ) treatment $48 \mathrm{~h}$ later by X-RAD 320, an X-ray irradiator (Precision X-Ray, North Branford, CT, USA). Mice were killed and necropsied at end points of either morbidity or mortality. Mouse tissues were extracted and processed as described in the Histology section.

Lymphocyte development, class switch recombination, and switch junction analyses. For analysis of lymphocyte development, single-cell suspensions were prepared from the bone marrow, thymus, and spleen from mice of 6-8 weeks old. $1 \times 10^{6}$ cells were stained by fluorescence-conjugated antibodies as indicated. Data were obtained by FACSCalibur flow cytometer (BD Biosciences) and interpreted by FLOWJO software (Tree Star, Ashland, OR, USA). For class switch recombination assays, splenic $\mathrm{CD} 43^{-} \mathrm{B}$ cells were isolated by immunomagnetic depletion using biotinylated anti-CD43 and streptavidin particles. Cells at $5 \times 10^{5} / \mathrm{ml}$ were stimulated for 4 days by $10 \mathrm{ng} / \mathrm{ml}$ of IL-4 plus $20 \mu \mathrm{g} / \mathrm{ml}$ of LPS in RPMI-1640-rich medium (containing $2 \mathrm{mM}$ L-glutamine, $10 \mathrm{mM}$ HEPES, $1 \mathrm{mM}$ sodium pyruvate, $4.5 \mathrm{~g} / \mathrm{l}$ glucose, and $1.5 \mathrm{~g} / /$ sodium bicarbonate) supplemented with $10 \%$ (vol/vol) fetal bovine serum (FBS) and $50 \mu \mathrm{M} \beta$ mercaptoethanol. Data were obtained by flow cytometry as described above. For $\mathrm{S} \mu-\mathrm{S} \gamma 1$ switch junction analysis, splenic $\mathrm{CD}^{-} 3^{-} \mathrm{B}$ cells were isolated and 
stimulated by IL-4 and LPS for 4 days as mentioned above. The $S \mu-S \gamma 1$ junction regions were amplified by PCR from extracted genomic DNA and cloned into PCR2.1 vector for sequencing using Topo-TA cloning kit (Invitrogen) as described previously. ${ }^{45}$ Sequence data were analyzed by pairwise sequence alignment tool (EMBOSS, EMBL-EBI) using GenBank files MUSIGCD07 (for $\mathrm{S} \mu$ ) and MUSIGHANB (for $\mathrm{S} \gamma 1$ ) for IgM and IgG1 switch regions, respectively.

Cell death assay. Isolated thymocytes were maintained ex vivo in RPMI-1640rich medium supplemented with $10 \% \mathrm{FBS}$ and $50 \mu \mathrm{M} \beta$-mercaptoethanol. Cells were either treated or non-treated by $\gamma$-irradiation using Cs137 based Gammacell 40 Exactor (Nordion International Inc., Ottawa, ON, Canada) at 0.78 Gy/min to induce DNA damage with dosage as indicated. Twenty-four hours later, cells were co-stained by Annexin V-FITC and PI or 7-AAD, and analyzed by flow cytometry. Proportion of live cells was determined by estimating percentage of cells negative to both Annexin $\mathrm{V}$ and $\mathrm{PI}$ (or 7-AAD) staining. The percentage of live cells was normalized by non-irradiated controls. For whole-body $\gamma$-irradiation, 4- to 6-week-old mice were $\gamma$-irradiated as described in the text and figure legends. The thymus was extracted from mice $24 \mathrm{~h}$ after IR treatment, stained, and analyzed as mentioned above. MCF10 cells were transfected with control and APLF siRNA. After $48 \mathrm{~h}$, the cells were treated by 2 Gy IR and apoptotic cells were quantified with Annexin $V$ and $\mathrm{PI}$ staining.

Histology. Thymus tissue was extracted from mice after $\gamma$-irradiation as described in the figure legends, fixed in neutral buffered formalin (Sigma), paraffinembedded, sectioned, and stained by TUNEL. Buffered formalin fixed femurs were paraffin-embedded after decalcified with 10\% EDTA, pH 7.4. Paraffin sections on slides were heated by microwave in $50 \mathrm{mM}$ citrate buffer for antigen retrieval. Sections were stained by antimyeloperoxidase (ab9535; Abcam, Cambridge, MA, USA) using the standard methods. DNA was counterstained by hematoxylin. Hematoxylin and eosin (H\&E) and Giemsa stainings of paraffin-embedded sections were prepared by standard procedures. Peripheral blood was collected by the cardiac puncture method and blood smears were stained by Wright's stain (EMD Millipore, Billerica, MA, USA) according to the supplier's protocol.

Extrachromosomal NHEJ assay. Primary MEFs of wild type and $\mathrm{Aplf}^{-1}$ mice were generated from mouse embryos at E13.5 and immortalized by SV40 T antigen using the standard method. Immortalized MEFs were maintained in DMEM high-glucose $(4.5 \mathrm{~g} / \mathrm{l})$ medium supplemented with $10 \%$ FBS and $0.8 \mu \mathrm{g} / \mathrm{ml}$ of puromycin. I-Scel-linearized $p E G F P-P e m 1-A d 2^{46}$ was co-transfected with $p D s R e d-$ Mono-N1 (Clontech, Mountain View, CA, USA), as the transfection control, into immortalized MEFs by Amaxa Nucleofector MEF 1 reagent (Lonza, Basel, Switzerland) following the manufacturer's manual. Cells were analyzed $48 \mathrm{~h}$ post transfection by flow cytometry using the FACSCalibur and FLOWJO software to estimate re-circularized pEGFP-Pem1-Ad2. Rejoining efficiency was determined by the ratio of $\mathrm{GFP}^{+} / \mathrm{RFP}^{+}$cells, relative to that of wild-type controls.

$\gamma \mathrm{H} 2 \mathrm{AX}$-positive cells quantification. Total bone marrow cells were extracted from femurs and tibias of mice using phosphate-buffered saline (PBS) supplemented with 1\% (vol/vol) FBS and 1 mM EDTA. After lysing red blood cells, $1 \times 10^{6} / \mathrm{ml}$ of nucleated cells were cultured in RPMI-1640-rich medium supplemented with $10 \%$ FBS and $50 \mu \mathrm{M} \beta$-mercaptoethanol, recombinant murine Flt3ligand ( $20 \mathrm{ng} / \mathrm{ml})$, IL-3 $(20 \mathrm{ng} / \mathrm{ml})$, IL-6 (20 ng/ml), SCF (20 ng/ml), TPO (50 ng/ml), and recombinant human TSLP (10 ng/ml) for $16 \mathrm{~h}$. After exposed to 2 Gy IR, bone marrow cells were harvested at indicated time points, fixed in $2 \%$ paraformaldehyde (Sigma), and permeabilized by $90 \%$ methanol. ${ }^{47}$ Fixed cells were then stained by anti- $\gamma \mathrm{H} 2 \mathrm{AX}$ (pS139) conjugated with Alexa Fluor 647 (BD Biosciences) at $4{ }^{\circ} \mathrm{C}$ for $1 \mathrm{~h}$, followed by PI $(30 \mu \mathrm{g} / \mathrm{ml})$ in the presence of $100 \mu \mathrm{g} / \mathrm{ml}$ RNase A (Thermo Scientific, Waltham, MA, USA) for $60 \mathrm{~min}$ at room temperature in dark. At least 10000 cells of each sample were analyzed as described ${ }^{47}$ by FACSCanto (BD Biosciences) and interpreted by FLOWJO software.

Cell cycle analysis. Red blood cell-depleted spleen cells were cultured at $1 \times 10^{6} / \mathrm{ml}$ in RPMI-1640-rich medium supplemented with $10 \% \mathrm{FBS}$ and $50 \mu \mathrm{M}$ $\beta$-mercaptoethanol, IL-4 $(10 \mathrm{ng} / \mathrm{ml})$, and LPS $(20 \mu \mathrm{g} / \mathrm{ml})$ for $48 \mathrm{~h}$. Cells were then irradiated (2 Gy, X-RAD 320), harvested at the indicated time as described in the text and figures, and fixed in ice-cold $70 \%$ ethanol. Fixed cells were stained by $\mathrm{PI}$ (27 $\mu \mathrm{g} / \mathrm{ml})$ in the presence of $100 \mu \mathrm{g} / \mathrm{ml}$ RNase A for $60 \mathrm{~min}$ at room temperature in dark. DNA content was measured by flow cytometry and analyzed by FLOWJO. To assess the G2/M checkpoint by flow cytometry, fixed cells were permeabilized in
0.1\% Triton X-100/PBS buffer for $15 \mathrm{~min}$ at room temperature before staining by Alexa Fluor 488-conjugated phospho-histone-H3 (pSer10) antibody (New England BioLabs, Ipswich, MA, USA).

Ex vivo bone marrow metaphase preparation. Total bone marrow cells were extracted from femurs and tibias of mice using PBS supplemented with $1 \%$ FBS and 1 mM EDTA. After lysing red blood cells, nucleated cells were cultured in RPMI-1640-rich medium supplemented with $10 \%$ FBS and $50 \mu \mathrm{M}$ $\beta$-mercaptoethanol, recombinant murine Flt3-ligand ( $20 \mathrm{ng} / \mathrm{ml}), \mathrm{LL}-3$ ( $20 \mathrm{ng} / \mathrm{ml})$, IL-6 (20 ng/ml), SCF $(20 \mathrm{ng} / \mathrm{ml})$, TPO $(50 \mathrm{ng} / \mathrm{ml})$, and recombinant human TSLP (10 ng/ $\mathrm{ml}$ ). After $24 \mathrm{~h}$, bone marrow cells were exposed to $2 \mathrm{~Gy} \mathrm{IR} \mathrm{(X-RAD} \mathrm{320).} \mathrm{One} \mathrm{hour}$ before harvesting cells, $150 \mathrm{ng} / \mathrm{ml}$ of colcemid (Roche, Basel, Switzerland) was added to the culture. Cells were then harvested, treated in $75 \mathrm{mM}$ potassium chloride $(\mathrm{KCl})$ at $37^{\circ} \mathrm{C}$ for $20 \mathrm{~min}$, and fixed with ice-cold methanol/acetic acid (3:1) fixative. Fixed cells were then dropped on slides to generate metaphase spreads. Slides were allowed to dry overnight and then mounted with Vectorshield containing DAPI (Vector Laboratories, Burlingame, CA, USA) for analysis. Images were taken with Axiolmager Z1 (Zeiss, Oberkochen, Germany) equipped with Metamorph software (Molecular Devices, Sunnyvale, CA, USA).

Direct bone marrow metaphase preparation. Total bone marrow cells from whole-body irradiated mice were extracted by RPMI-1640-rich medium supplemented with $10 \% \mathrm{FBS}, 50 \mu \mathrm{M} \beta$-mercaptoethanol, and $10 \mathrm{U}$ heparin $/ \mathrm{ml}$ (Sigma). Cells were treated in $75 \mathrm{mM} \mathrm{KCl}$ containing $40 \mathrm{ng} / \mathrm{ml}$ of colcemid at $37^{\circ} \mathrm{C}$ for $20 \mathrm{~min}$, fixed with ice-cold methanol/acetic acid, and dropped on slides. Air-dried slides were processed for two- and three-color FISH or three-color whole chromosome paint as described below.

Multicolor FISH (M-FISH). Red blood cell-depleted spleen cells were cultured in RPMI-1640-rich medium supplemented with $10 \%$ FBS and $50 \mu \mathrm{M}$ $\beta$-mercaptoethanol, recombinant murine Flt3-ligand $(20 \mathrm{ng} / \mathrm{ml}), \mathrm{IL}-3(20 \mathrm{ng} / \mathrm{ml}), \mathrm{IL}-6$ $(20 \mathrm{ng} / \mathrm{ml})$, SCF $(20 \mathrm{ng} / \mathrm{ml})$, TPO $(50 \mathrm{ng} / \mathrm{ml}), \mathrm{lL}-4(10 \mathrm{ng} / \mathrm{ml})$, recombinant human TSLP $(10 \mathrm{ng} / \mathrm{ml})$, and LPS $(20 \mu \mathrm{g} / \mathrm{ml})$ for $48 \mathrm{~h}$. One hour before harvesting cells, $150 \mathrm{ng} / \mathrm{ml}$ of colcemid (Roche) was added to the culture. Cells were then harvested, treated in $75 \mathrm{mM}$ potassium chloride $(\mathrm{KCl})$ at $37^{\circ} \mathrm{C}$ for $20 \mathrm{~min}$, and fixed with icecold methanol/acetic acid (3:1) fixative. Fixed cells were then dropped on slides. Slides containing metaphases were stained with mouse m-FISH kit (21XMouse) to identify chromosome aberrations according to the supplier's protocol (MetaSystems, Altussheim, Germany). Metaphase spreads were captured at $\times 630$ magnification on an Imager M1 Zeiss microscope (Carl Zeiss Canada Limited, Toronto, ON, Canada) equipped with the appropriate filters. The JAI CV-M4+CL progressive scan monochrome camera (JAI Inc., San Jose, CA, USA) and the MetaSystems Isis FISH Imaging software programs v5.3 (MetaSystems) were used for analysis. Gene-specific probes were applied, as described below, to confirm specific translocations as M-FISH has some limitations in delineations of chromosomal rearrangements.

Mouse BAC clones probe preparation. Mouse BAC clones encompass the locus containing Hoxb (RP23-205E11 and RP23-9G13), Ets1 (RP23-403F11 and RP23-101N3), Sept4 (RP23-333D13), or Rara (RP23-333D2 and RP23364P11). BAC clones were verified by PCR using primers against regions of each gene. Probes were prepared by nick translation kit using green dUTP, orange dUTP, or Aqua dUTP according to the manufacturer's protocol (Abbott Molecular, Des Plaines, IL, USA). At least $100 \mathrm{ng}$ of each probe was used in hybridization.

Two- and three-color FISH. Metaphases on slides were treated by $100 \mu \mathrm{g} /$ $\mathrm{ml}$ RNase A (Thermo Scientific) in $2 \times$ SSC for $1 \mathrm{~h}$ at $37^{\circ} \mathrm{C}$, washed $2 \times 5 \mathrm{~min}$ in $2 \times$ SSC. Fixed in $4 \%$ formaldehyde for $10 \mathrm{~min}$. Washed $2 \times 5 \mathrm{~min}$ in $2 \times$ SSC and dehydrated in 70,90 , and $100 \%$ ethanol. The slides were then treated with $70 \%$ formamide in $2 \times \mathrm{SSC}$ at $75^{\circ} \mathrm{C}$ for $5 \mathrm{~min}$. Rinsed briefly in cold $2 \times \mathrm{SSC}$, once in $70 \%$ ethanol $\left(5 \mathrm{~min},-20{ }^{\circ} \mathrm{C}\right)$, and dehydrated with 90 and $100 \%$ ethanol at room temperature. Fluorescent probes were denatured in 50\% Formamide, 10\% (w/v) dextran sulfate, $1 \times$ SSC and $20 \times\left(\mathrm{w} / \mathrm{w}\right.$ ) mouse Cot 1 DNA (Invitrogen) at $75^{\circ} \mathrm{C}$ for $10 \mathrm{~min}$, applied to the slides, and incubated overnight in a humidified chamber at $37^{\circ} \mathrm{C}$. Slides were then washed once in $0.4 \times \mathrm{SSC} / 0.3 \%$ Tween 20 at $74^{\circ} \mathrm{C}$ for $5 \mathrm{~min}$ and once in $4 \times \mathrm{SSC} / 0.1 \%$ Tween 20 at room temperature for $2 \mathrm{~min}$. Dehydrated, air dried, and mounted with Vectorshield containing DAPI. Images were obtained using Axiolmager Z1 equipped with Metamorph software. 
Whole chromosome paint. Metaphases were stained by 3-color whole mouse chromosome paint (Applied Spectral Imaging, Carlsbad, CA, USA) in red (chromosome 2 or 9), green (chromosome 6 or 11), and aqua (chromosome 12 or 15) or by three-color whole human chromosome paint (Applied Spectral Imaging) in red (chromosome 8 or 11), green (chromosome 5 or 21), and aqua (chromosome 7 or 15) according to the manufacturer's protocol. Slides were counterstained with Vectorshield containing DAPI. Images were obtained using Axiolmager Z1 equipped with Metamorph software.

MCF10A cell culture. MCF10a cells were maintained in DMEM/F12 medium supplemented by $2 \mathrm{mM}$ L-glutamine, $5 \%$ horse serum (Life Technologies), $20 \mathrm{ng} / \mathrm{ml}$ epidermal growth factor (Peprotech), $0.5 \mu \mathrm{g} / \mathrm{ml}$ hydrocortisone (Sigma), $0.1 \mu \mathrm{g} / \mathrm{ml}$ cholera toxin (Sigma), $10 \mu \mathrm{g} / \mathrm{ml}$ insulin (Sigma), and $50 \mathrm{U} / \mathrm{ml}$ of penicillinstreptomycin.

siRNA knockdown of APLF. All siRNA pools were obtained from Dharmacon. For every experiment, $25 \mathrm{nM}$ of four siRNA sequences were used to transfect cells by Dharmafect 1 (Dharmacon, Lafayette, CO, USA) according to the manufacturer's protocol. Cells were treated by 2 Gy IR or harvested for western blot $48 \mathrm{~h}$ after.

siRNA sequences against: human APLF, GCACAAGAUAGAAUAUAGA, CUUCAUAUUACGUGACUUU, AGCAAUCAGUGGAGGUAAU, UGAUUAUGGAGG UGUACAA, and non-targeting control, UGGUUUACAUGUCGACUAA, UGGUUUAC AUGUUGUGUGA, UGGUUUACAUGUUUUCUGA, UGGUUUACAUGUUUUCCUA.

Statistical analysis. Differences between groups were assayed using an unpaired two-tailed Student's $t$-test after evaluation of variance. In cases where the assumption of the t-test was not valid, the non-parametric two-tailed Mann-Whitney test was used. Multiple groups were analyzed by one-way ANOVA with Tukey's post hoc test. A two-tailed Fisher's exact test was used to analyze the contingency table of microhomology length at switch junctions. Survival differences were analyzed by log-rank test. $P<0.05$ was considered statistically significant.

\section{Conflict of Interest}

The authors declare no conflict of interest.

Acknowledgements. We thank A Wakeham for his help in microinjection for generating Aplf chimera mice, V Gorbunova for sharing pEGFP-Pem1-Ad2 plasmid, D Durocher and M Kawazu for comments to the manuscript, O Ludkovski for performing M-FISH analysis and J Haight for help. This work was supported by a ClHR grant (MOP84353) to $\mathrm{HO}$ and was also supported in part by the MEXT-Support Program for the Strategic Research Foundation at Private Universities and Grant-inAid for Scientific Research to HO. KIT was supported by a postdoctoral fellowship from the Canadian Breast Cancer Foundation.

1. Travis LB, Demark Wahnefried W, Allan JM, Wood ME, Ng AK. Aetiology, genetics and prevention of secondary neoplasms in adult cancer survivors. Nat Rev Clin Oncol 2013; 10: 289-301.

2. Czader M, Orazi A. Therapy-related myeloid neoplasms. Am J Clin Pathol 2009; 132 410-425.

3. Travis LB, Rabkin CS, Brown LM, Allan JM, Alter BP, Ambrosone CB et al. Cancer survivorship - genetic susceptibility and second primary cancers: research strategies and recommendations. J Natl Cancer Inst 2006; 98: 15-25.

4. Wong TN, Ramsingh G, Young AL, Miller CA, Touma W, Welch JS et al. Role of TP53 mutations in the origin and evolution of therapy-related acute myeloid leukaemia. Nature 2015; 518: 552-555.

5. Rooney S, Chaudhuri J, Alt FW. The role of the non-homologous end-joining pathway in lymphocyte development. Immunol Rev 2004; 200: 115-131.

6. Deriano L, Roth DB. Modernizing the non-homologous end-joining repertoire: alternative and classical NHEJ share the stage. Annu Rev Genet 2013; 47: 433-544.

7. Yan CT, Boboila C, Souza EK, Franco S, Hickernell TR, Murphy M et al. IgH class switching and translocations use a robust non-classical end-joining pathway. Nature 2007; 449: 478-482.

8. Ahel I, Ahel D, Matsusaka T, Clark AJ, Pines J, Boulton SJ et al. Poly(ADP-ribose)-binding zinc finger motifs in DNA repair/checkpoint proteins. Nature 2008; 451: 81-85.

9. Macrae CJ, McCulloch RD, Ylanko J, Durocher D, Koch CA. APLF (C2orf13) facilitates nonhomologous end-joining and undergoes ATM-dependent hyperphosphorylation following ionizing radiation. DNA Repair (Amst) 2008; 7: 292-302.
10. Rulten SL, Fisher AE, Robert I, Zuma MC, Rouleau M, Ju L et al. PARP-3 and APLF function together to accelerate nonhomologous end-joining. Mol Cell 2011; 41: 33-45.

11. Fenton AL, Shirodkar P, Macrae CJ, Meng L, Koch CA. The PARP3- and ATM-dependent phosphorylation of APLF facilitates DNA double-strand break repair. Nucl Acids Res 2013; 41: 4080-4092.

12. Shirodkar $P$, Fenton $A L$, Li M, Koch CA. Identification and functional characterization of a kubinding motif in Aprataxin Polynucleotide Kinase/Phosphatase-like Factor (APLF). J Biol Chem 2013; 288: 19604-19613.

13. Bassing $\mathrm{CH}$, Swat $\mathrm{W}$, Alt FW. The mechanism and regulation of chromosomal V(D)J recombination. Cell 2002; 109: S45-S55.

14. Chaudhuri J, Basu U, Zarrin A, Yan C, Franco S, Perlot $T$ et al. Evolution of the immunoglobulin heavy chain class switch recombination. Adv Immunol 2007; 94: 157-214.

15. Rooney S, Sekiguchi J, Zhu C, Cheng HL, Manis J, Whitlow S et al. Leaky Scid phenotype associated with defective $\mathrm{V}(\mathrm{D}) \mathrm{J}$ coding end and processing in Artemis-deficient mice. Mo Cell 2002; 10: 1379-1390.

16. Ciccia A, Elledge SJ. The DNA damage response: making it safe to play with knives. Mol Cell 2010; 40: 179-204.

17. Reinhardt HC, Schemacher B. The p53 network: cellular and systemic DNA damage responses in aging and cancer. Trends Genet 2012; 28: 128-136.

18. Mukherjee B, Kessinger C, Kobayashi J, Chen BP, Chen DJ, Chatterjee A et al. DNA-PK phosphorylates histone $\mathrm{H} 2 \mathrm{AX}$ during apoptotic DNA fragmentation in mammalian cells. DNA Repair 2006; 5: 575-590.

19. Blankenbecler R. Low-dose pretreatment for radiation therapy. Dose Response 2010; 8 : 534-542.

20. Shadley JD, Dai G. Cytogenetic and survival adaptive responses in $\mathrm{G} 1$ phase human lymphocytes. Mutat Res 1992; 265: 273-281.

21. Kogan SC, Ward JM, Anver MR, Berman JJ, Brayton C, Cardiff RD et al. Bethesda proposals for classification of nonlymphoid hematopoietic neoplasms in mice. Blood 2002; 100 : 238-245.

22. Donehower LA, Harvey M, Slagle BL, McArthur MJ, Montgomery CA Jr, Butel JS et al. Mice deficient for p53 are developmentally normal but susceptible to spontaneous tumours. Nature 1992; 356: 215-221.

23. Petrini M, Felicetti F, Bottero L, Errico MC, Morsilli O, Boe A et al. HOXB1 restored expression promotes apoptosis and differentiation in the HL60 leukemic cell line. Cancer Cell Int 2013; 13: 101.

24. Yan-Fang T, Dong W, Li P, Wen-Li Z, Jun L, Na W et al. Analyzing the gene expression profile of pediatric acute myeloid leukemia with real-time PCR arrays. Cancer Cell In 2012; 12: 40.

25. Zelent A, Guidez F, Melnick A, Waxman S, Licht JD. Translocations of the RARa gene in acute promyelocytic leukemia. Oncogene 2001; 20: 7186-7203.

26. Diaz MO, Le Beau MM, Pitha P, Rowley JD. Interferon and c-ets-1 genes in the translocation $(9 ; 11)($ p22;q23) in human acute monocytic leukemia. Science 1986; 231: 265-267.

27. Zhu C, Mills KD, Ferguson DO, Lee C, Manis J, Fleming J et al. Unrepaired DNA breaks in p53-deficient cells lead to oncogenic gene amplification subsequent to translocations. Cell 2002; 109: 811-821.

28. Robbiani DF, Bothmer A, Callen E, Reina-San-Martin B, Dorsett Y, Difilippantonio S et al. AID is required for the chromosomal breaks in c-myc that lead to c-myc/lgH translocations. Cell 2008; 135: 1028-1038.

29. Bunting SF, Nussenzweig A. End-joining, translocations and cancer. Nat Rev Cancer 2013; 13: 443-454.

30. Chiang C, Jacobsen JC, Ernst C, Hanscom C, Heilbut A, Blumenthal I et al. Complex reorganization and predominant non- homologous repair following chromosomal breakage in karyotypically balanced germline rearrangements and transgenic integration. Nat Genet 2012; 44: 390-397.

31. Berger MF, Lawrence MS, Demichelis F, Drier Y, Cibulskis K, Sivachenko AY et al. The genomic complexity of primary human prostate cancer. Nature 2011; 470: 214-220.

32. Stephens PJ, McBride DJ, Lin ML, Varela I, Pleasance ED, Simpson JT et al. Complex landscapes of somatic rearrangement in human breast cancer genomes. Nature 2009; 462 1005-1010.

33. Waddell N, Pajic M, Patch AM, Chang DK, Kassahn KS, Bailey P et al. Whole genomes redefine the mutational landscape of pancreatic cancer. Nature 2015; 518: 495-501.

34. Ferguson DO, Sekiguchi JM, Chang S, Frank KM, Gao Y, DePinho RA et al. The nonhomologous end-joining pathway of DNA repair is required for genomic stability and the suppression of translocations. Proc Natl Acad Sci USA 2000; 97: 6630-6633.

35. Difilippantonio MJ, Petersen S, Chen HT, Johnson R, Jasin M, Kanaar R et al. Evidence for replicative repair of DNA double-strand breaks leading to oncogenic translocation and gene amplification. J Exp Med 2002; 196: 469-480.

36. Simsek D, Jasin M. Alternative end-joining is suppressed by the canonical NHEJ component Xrcc4-ligase IV during chromosomal translocation formation. Nat Struct Mol Biol 2010; 17 $410-416$.

37. Zhang $Y$, Jasin M. An essential role for CtIP in chromosomal translocation formation through an alternative endjoining pathway. Nat Struct Mol Biol 2011; 18: 80-84.

38. Christiansen DH, Andersen MK, Pedersen-Bjergaard J. Mutations with loss of heterozygosity of p53 are common in therapy-related myelodysplasia and acute myeloid leukemia after exposure to alkylating agents and significantly associated with deletion or loss of 5q, a complex karyotype, and a poor prognosis. J Clini Oncol 2001; 19 : 1405-1413. 
39. Pedersen-Bjergaard J, Christiansen DH, Desta F, Andersen MK. Alternative genetic pathways and cooperating genetic abnormalities in the pathogenesis of therapy-related myelodysplasia and acute myeloid leukemia. Leukemia 2006; 20: 1943-1949.

40. Li T, Kon N, Jiang L, Tan M, Ludwig T, Zhao Y et al. Tumor suppression in the absence of p53-mediated cell-cycle arrest, apoptosis, and senescence. Cell 2012; 149: 1269-1283.

41. Chao C, Herr D, Chun J, Xu Y. Ser18 and 23 phosphorylation is required for p53-dependent apoptosis and tumor suppression. EMBO J 2006; 25: 2615-2622.

42. Armata HL, Garlick DS, Sluss HK. The ataxia-telangiectasia-mutated target site Ser18 is required for p53-meidated tumor suppression. Cancer Res 2007; 67: 11696-11703.

43. Gudkov AV, Komarova EA. Dangerous habits of a security guard: the two faces of $p 53$ as a drug target. Human Molecular Genetics 2007; 16: R67-R72.

44. Herzog KH, Chong MJ, Kapsetaki M, Morgan Jl, McKinnon PJ. Requirement for Atm in ionizing radiation-induced cell death in the developing central nervous system. Science 1998; 280: 1089-1091.

45. Ehrenstein MR, Rada C, Jones AM, Milstein C, Neuberger MS. Switch junction sequences in PMS2-deficient mice reveal a microhomology-mediated mechanism of $\mathrm{lg}$ class switch recombination. Proc Natl Acad Sci USA 2001; 98: 14553-14558.

46. Seluanov A, Mittelman D, Pereira-Smith OM, Wilson JH, Gorbunova V. DNA end joining becomes less efficient and more error-prone during cellular senescence. Proc Natl Acad Sci USA 2004; 101: 7624-7629.
47. Kataoka Y, Bindokas VP, Duggan RC, Murley JS, Grdina DJ. Flow cytometric analysis of phosphorylated histone $\mathrm{H} 2 \mathrm{AX}$ following exposure to ionizing radiation in human microvascular endothelial cells. J Radiat Res 2006; 47: 245-257.

Cell Death and Disease is an open-access journal published by Nature Publishing Group. This work is licensed under a Creative Commons Attribution 4.0 International License. The images or other third party material in this article are included in the article's Creative Commons license, unless indicated otherwise in the credit line; if the material is not included under the Creative Commons license, users will need to obtain permission from the license holder to reproduce the material. To view a copy of this license, visit http://creativecommons.org/licenses/by/4.0/

(C) The Author(s) 2016

Supplementary Information accompanies this paper on Cell Death and Disease website (http://www.nature.com/cddis) 